\title{
Probabilistic evaluation of the physical impact of future tephra fallout events for the Island of Vulcano, Italy
}

\author{
Sebastien Biass • Costanza Bonadonna • \\ Federico di Traglia . Marco Pistolesi . \\ Mauro Rosi • Pierino Lestuzzi
}

Received: date / Accepted: date

\begin{abstract}
A first probabilistic scenario-based hazard assessment for tephra fallout is presented for La Fossa volcano (Vulcano Island, Italy) and subsequently used to assess the impact on the built environment. Eruption scenarios are based upon the stratigraphy produced by the last 1,000 years of activity at Vulcano and include long-lasting Vulcanian and sub-Plinian eruptions. A new method is proposed to quantify the evolution through time of the hazard associated with pulsatory Vulcanian eruptions lasting from weeks to years, and the increase in hazard related to typical rainfall events around Sicily is also accounted for. The impact assessment on the roofs is performed by combining a field characterization of the buildings with the composite European vulnerability curves for typical roofing stocks. Results show that a sub-Plinian eruption
\end{abstract}

S. Biass

Department of Earth Sciences, University of Geneva, Switzerland

Present address: Department of Earth Sciences, University of Hawai'i at Manoa, Honolulu, Hawai'i, USA

E-mail: sbiasse@hawaii.edu

C. Bonadonna

Department of Earth Sciences, University of Geneva, Switzerland

F. Di Traglia

Earth Sciences Department, University of Florence, Florence, Italy

M. Pistolesi

Earth Sciences Department, University of Florence, Florence, Italy

M. Rosi

Italian Civil Protection, Roma, Italy

P. Lestuzzi

EPFL, ENAC IIC IMAC, Lausanne, Switzerland 
of VEI 2 is not likely to affect buildings, whereas a sub-Plinian eruption of VEI 3 results in $90 \%$ of the building stock having a $\geq 12 \%$ probability of collapse. The hazard related to long-lasting Vulcanian eruptions evolves through time, and our analysis shows that the town of Il Piano, located downwind of the preferential wind patterns, is likely to reach critical tephra accumulations for roof collapse 5-9 months after the onset of the eruption. If no cleaning measures are taken, half of the building stock has a probability $>20 \%$ of suffering roof collapse.

Keywords Probabilistic hazard assessment - Tephra · Physical vulnerability · Roof collapse $\cdot$ Modelling $\cdot$ Impact $\cdot$ La Fossa

\section{Introduction}

Volcanic eruptions are typically associated with multiple hazards which, combined with the rapid increase of human settlements in areas of active volcanism (Chester et al, 2000) and increasingly vulnerable technologies, infrastructure, and aviation transportation, pose short- and long-term threats to societies. Warnings preceding eruptions may vary from minutes to days, with most volcanic eruptions reaching their peak intensity shortly after the onset of unrest, leaving the time only for predetermined plans of action (Newhall, 2000; De La Cruz-Reyna et al, 2000). There is therefore a need for communities to be trained and prepared in advance to respond to volcanic unrest. Building such preparedness is, however, problematic because of the relatively infrequent occurrence of large explosive volcanic eruptions globally, which results in limited experiences with emergency planning and mitigation compared to more frequent hazards, such as hurricanes or floods. The level of success in management of a volcanic crisis thus strongly correlates with the degree to which proactive policies of risk reduction are implemented before an eruption (Chester et al, 2002). The implementation of such a concept requires both knowledge of the probability of occurrence and spatial extent of likely hazardous phenomena and knowledge of the exposed systems (i.e. socio-economical characteristics of exposed communities, physical state of the built environment, systemic importance of critical infrastructures).

Amongst all volcanic phenomena, tephra fallout can affect the largest areas, with associated patterns of hazards varying with distance from the vent (Jenkins et al, 2014; Wilson et al, 2011). Simkin and Siebert (1994) report that, although tephra fallout has been estimated to be responsible for only $2 \%$ of recorded fatalities since $\mathrm{AD} 1$, it has been the most frequent cause of death, reported in $21 \%$ of eruptions, mainly due do entrapment following the collapse of buildings under a load (Blong, 1984). Assessing the vulnerability of the built environment to tephra fallout is therefore a crucial aspect to consider when developing integrated proactive risk mitigation strategies. The vulnerability of the built environment is typically expressed as its propensity to suffer damage which, combined with hazard assessment, can be translated into an estimation of the risk (Spence et al, 2007, 2005; Douglas, 2007). It is worth noting that 


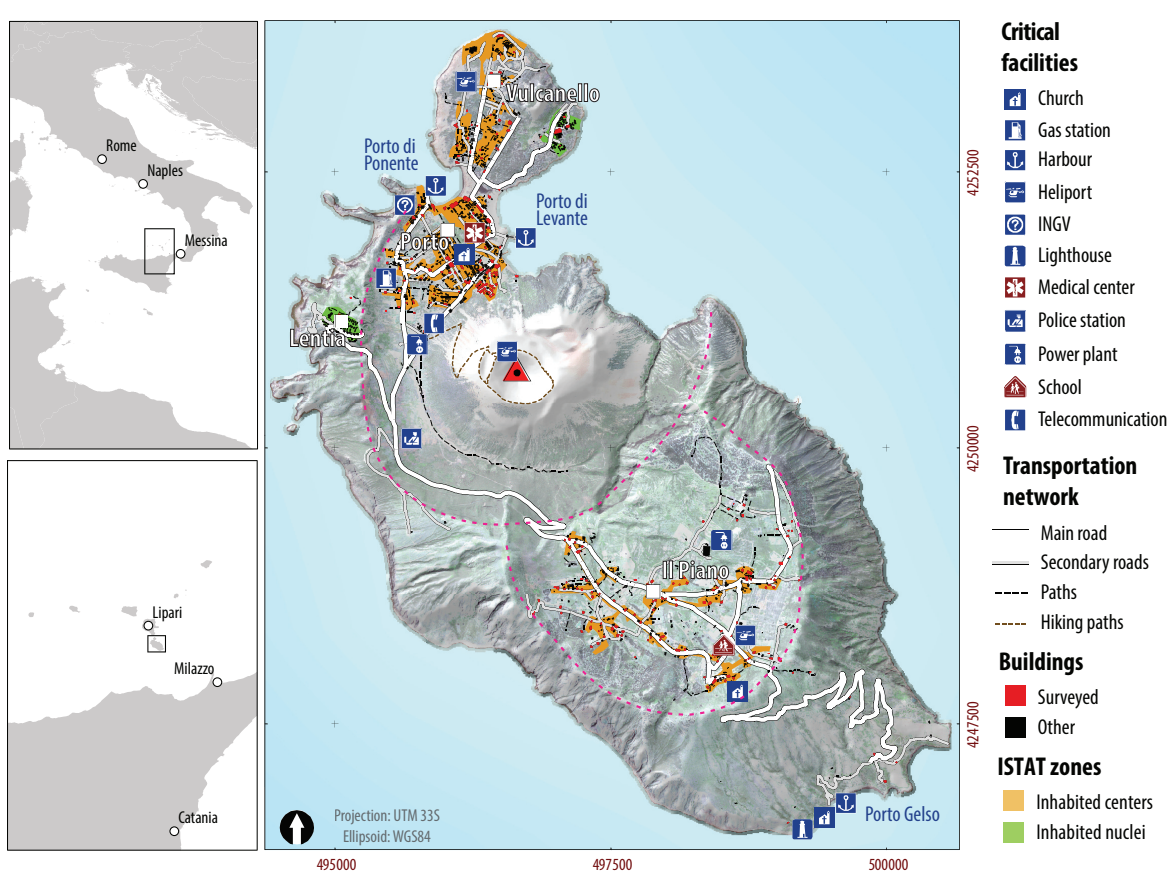

Fig. 1 Overview of Vulcano Island, showing the road network, the location of critical infrastructures, the buildings footprints and the types of urban areas as defined by ISTAT (2005). The dashed purple lines show the approximative limits of the Piano (South) and La Fossa (North) calderas. The school and the medical centre will be used as key locations throughout the paper.

at least three schools of thought exist in volcanology regarding assessment of impacts on the built environment. Some authors express the impact as a loss of economical value. For instance Blong (2003b,a) builds a classification scheme based on a review of existing damage indices, which express the impact ranging from aesthetic aspects to total collapse. Other authors aim to quantify the loss of life related to building collapse, and tend to develop fragility curves expressing the probability of collapse given the occurrence of a hazard of a given magnitude (e.g. Spence et al, 2005, 2007; Jenkins et al, 2014). More recently, new damage scales have been developed to relate the direct physical impact to the loss of function of a given building, thus underlining the importance of critical infrastructures in a concept of systemic vulnerability (Menoni et al, 2012; Jenkins et al, 2015; Wilson et al, 2011).

Due to the rare occurrence of volcanic eruptions, only a few detailed damage assessments exist in the literature to better constrain the degree of building damage in relation to the severity of specific volcanic hazards (e.g. Spence et al, 1996 after the 1991 eruption of Pinatubo and Blong, 2003c after the 1994 eruption of Rabaul). In terms of physical risk assessment in volcanology, Pomonis et al (1999) produced one of the first comprehensive assessments of the building stock around Furnas volcano (Azores) by conducting an in-depth 
study of the building typology and likely performance in the face of an eruption similar to that of 1630 AD. Additionally, GIS-based impacts assessments of future eruptions were produced for La Soufrire of Guadeloupe (Lesser Antilles; Spence et al, 2008) and Vesuvius (Italy; Zuccaro et al, 2008).

The active vent of Vulcano, La Fossa, last erupted in 1888-1890 in a 2 yearlong Vulcanian eruption characterized by emission of ballistics, intermittent tephra fallouts and intense remobilization of tephra deposits into lahars and hyperconcentrated flows (Mercalli and Silvestri, 1891; De Fiore, 1922; Fiorillo and Wilson, 2004; Di Traglia et al, 2013). Following this eruption, the first urbanization wave took place after the 1950s in the Porto area (Fig. 1) without consideration of volcanic hazards in the land-use planning, resulting in urban areas located as close as 700 metres away from the crater. Three evacuation harbours exist on the island, which potentially become unusable during episodes of extreme wind conditions, reinforcing the necessity of assessing the vulnerability of the built environment to volcanic hazards in order to identify potential shelters.

As a first step towards a proactive risk-mitigation strategy for Vulcano Island, we present here a comprehensive hazard assessment for tephra fallout and a subsequent physical impact assessment focused only on the built environment. Section 2 presents the case-study of Vulcano Island and reviews the stratigraphy and the activity of the past 1,000 years (Di Traglia et al, 2013; De Astis et al, 2013), which is used as a basis to develop eruption scenarios. Section 3 describes the hazard assessment compiled using the advection-diffusion model TEPHRA2 coupled with probabilistic strategies to assess the preferential dispersal and sedimentation of tephra for various short-lasting subPlinian and long-lasting Vulcanian eruptions (Bonadonna, 2006; Bonadonna et al, 2005). Section 4 presents the vulnerability assessment of the built environment on Vulcano based on a field survey and the typical roofing stocks of Spence et al (2005). Finally, section 5 combines hazard and vulnerability assessments in order to quantify the potential number of building collapses following tephra fallout associated with the identified eruption scenarios. Although the pre-event impact assessment considered here is purely physical (i.e., associated with potential physical damage of buildings and infrastructures and without without considering the impact on other sectors, such as tourism and transportation), it provides a first step on which both mitigation strategies and resilience can be developed.

\section{Case study}

Vulcano is one of the seven islands of the Aeolian archipelago in the Tyrrhenian Sea of southern Italy (Fig. 1). Tourism became the primary economic activity in the 1950s in all Aeolian Islands, but the main urbanization wave on Vulcano took place in the 1980s. Since then, development has progressed rapidly without consideration of volcanic hazards in land-use planning. The population on Vulcano subsists on tourism between April and October when the island's 
population swells to as many as 20,000. The $\sim 800$ permanent residents are equally distributed between the two principal towns on the island, Il Porto and Il Piano, but most tourist infrastructures are located in the area of Porto di Levante (known locally as Porto), beneath the lowest flank of La Fossa cone (Fig. 1), the most active volcanic system on the island at present time. The seasonal variation of population size significantly increases the volcanic risk in the summer months. Critical facilities are also equally distributed between Il Porto and Il Piano area, resulting in a complex territorial vulnerability associated with different eruptive scenarios. The potential for short warning times and proximity of people on the island to hazards associated with an eruption exacerbate the risk to people and property on the island.

Since the end of the last magmatic eruption in 1890, activity at La Fossa cone has consisted of fumarolic emissions, earthquakes and accompanying landslides (posing a threat of tsunamis), and ground deformation (Barberi et al, 1991). Fumarolic fluids are discharged almost totally in two main fumarolic fields located in the northern rim of the active crater of La Fossa cone and at the beach of Baia di Levante (Porto area). About $98 \%$ by volume of the crater fumaroles contain $\mathrm{H}_{2} \mathrm{O}$ and $\mathrm{CO}_{2}$ with a maximum recorded temperature of $690{ }^{\circ} \mathrm{C}$ (Chiodini et al, 1995). The crater fumaroles result from the mixing of deep magmatic gases, shallow hydrothermal-brine gases and meteoric water. Unrest mostly consists of increasing fumarolic activity and significant fluctuations in the physico-chemical characteristics of the fumarolic system (Barberi et al, 1991; Granieri et al, 2006).

\subsection{Geological background}

The Island of Vulcano, together with Stromboli and Lipari, is one of the active volcanic islands of the Aeolian Archipelago (Southern Italy; Fig. 1). The volcanic complex is composed of several edifices that have overlapped in time and space since $120 \mathrm{ka}$ (Keller, 1980; De Astis et al, 2013). The two most recent volcanoes are the La Fossa cone, a 391-m-high active composite cone, that started to erupt $5.5 \mathrm{ka}$ ago (Frazzetta et al, 1984), and Vulcanello, a small volcanic system that erupted between the $11^{\text {th }}$ and the $17^{\text {th }}$ centuries (Arrighi et al, 2006; Di Traglia et al, 2013; Davi et al, 2009; Fusillo et al, 2015).

The eruptive history and structure of La Fossa cone was the topic of multiple studies (Arrighi et al, 2006; De Astis et al, 2013; Di Traglia et al, 2013; Frazzetta et al, 1984, 1983; Keller, 1970, 1980; Dellino et al, 2011). The last 1,000 years of activity includes several tephra fallout events of Vulcanian to sub-Plinian styles (Di Traglia et al, 2013; De Astis et al, 2013), the emplacement of series of PDCs (Gurioli et al, 2012; Dellino and La Volpe, 1997; Dellino et al, 2011) and several lava flows (Keller, 1980; Piochi et al, 2009; Di Traglia et al, 2013). Several lahar deposits resulting from the reworking of material originating from the La Fossa cone and the two Forgia excentric vents are also intercalated within the tephra sequence (Di Traglia et al, 2013). 

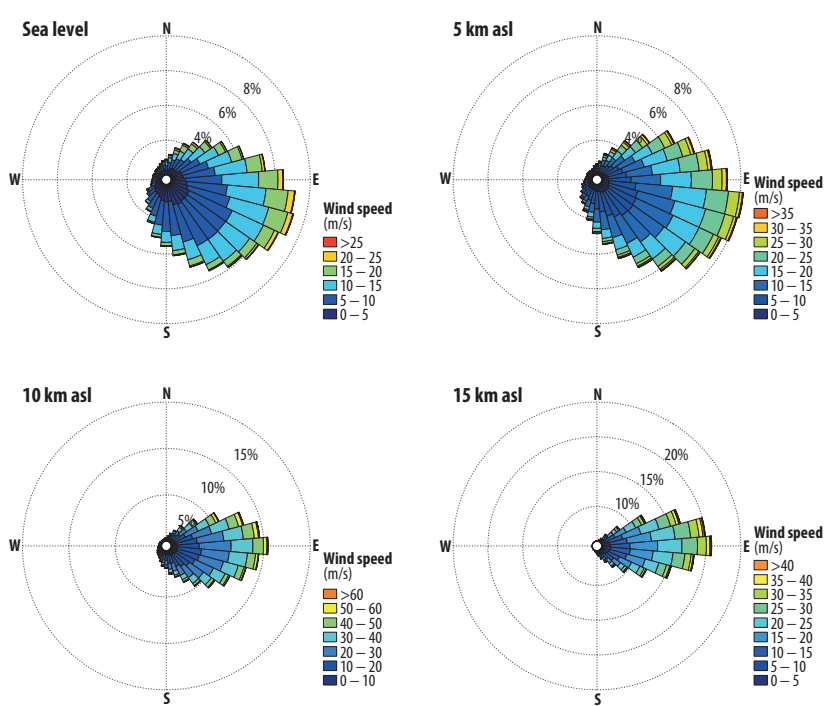

Fig. 2 Wind conditions inferred from the ECMWF ERA-Interim database for the period 1980-2010 at four different heights. Roses show the probability of wind blowing in a given direction (i.e. provenance + $180^{\circ}$ ) for a given velocity. Bins are $10^{\circ}$.

\subsubsection{The activity of the last 1000 years}

The catalogue of eruptions of the last 1,000 years was compiled using recent stratigraphic reconstructions (Di Traglia et al, 2013; De Astis et al, 2013) and the historical chronicles of Mercalli and Silvestri (1891) and De Fiore (1922). Following the nomenclature defined by Dellino and La Volpe (1997) and De Astis et al (2013), the period considered here is included within the Vallonazzo synthem (Gran Cratere di La Fossa). Di Traglia et al (2013) note that the base of the recent eruptive epoch at Vulcano can be recognized in the field by an important first order unconformity dated about 1,000 years old. The more recent deposits have been grouped into two main stratigraphic clusters, the Palizzi-Commenda Eruptive Cluster (PCEC) and the Gran Cratere Eruptive Cluster (GCEC), separated by a second order unconformity.

The first part of the PCEC is the Palizzi unit, which lasted for about a century (Arrighi et al, 2006; Di Traglia et al, 2013), is characterized by shifts in intensity including effusive, Strombolian and sub-Plinian events. After a long-lasting initial phase of mafic ash emissions, a first rhyolitic sub-Plinian eruption occurred (PAL B; Di Traglia et al, 2013), followed by a period of reworking of the newly formed material. After a new episode of long-lasting mafic ash emission, a second sub-Plinian eruption of trachytic composition occurred (PAL D; Di Traglia et al, 2013), followed by the effusion of two lava flows. The characterization of the two sub-Plinian tephra deposits show similarities in plume height (7-8 km a.s.l.) and erupted volume $\left(3.6-4.0 \times 10^{6} \mathrm{~m}^{3}\right.$; Di Traglia, 2011). The second part of the PCEC includes the Breccia di Commenda event ( 1240AD), which is characterized by tephra fallouts, ballistic ejections and PDCs (Gurioli et al, 2012). 
The GCEC, spanning from approximately 1440AD to 1890AD (Di Traglia et al, 2013), comprises at least 9 eruptions, the deposits of which are separated by low-order unconformities and that were mostly formed by repetitive Vulcanian activity rarely associated with PDCs. The GCEC ended with the last eruption of La Fossa in 1888-1890, described by Mercalli and Silvestri (1891) as Vulcanian because "[...] it is not comparable to other styles of activity identified on volcanoes. [...] although it never reached the intensity of Plinian styles, it nevertheless reached an equal majesty at the beginning which, together with the strength of the projectile, makes it larger than a Strombolian type [...]". Di Traglia et al (2013) recognizes the onset of the GCEC as being the steam-blast eruption of Forgia that occurred on the $5^{\text {th }}$ of February 1444 (Mercalli and Silvestri, 1891), followed by the first Vulcanian eruption of the Piettre Cotte cycle around 1550AD, marking the onset of a series of eight Vulcanian eruptions lasting from weeks to years. Volumes of tephra estimated by Di Traglia (2011) range from $10^{6}$ to $10^{8} \mathrm{~m}^{3}$, calculated from empirical methods (Bonadonna and Houghton, 2005; Pyle, 1989). One lava flow (Pietre Cotte lava flow) was erupted during the 1731-1739 eruption (Arrighi et al, 2006). Additional observations of the last 1888-1890 eruption are provided by Mercalli and Silvestri (1891) and compiled in the work of Bianchi (2007), which report plume heights comprised between 1-10 km above sea level, and a positive relationship between the repose interval between explosions and the plume height of the following plume (i.e. longer repose intervals result in higher plumes).

\subsection{Built environment}

The 2000 census of the Italian Instituto Nazionale di Statistica (ISTAT, 2005) identifies three distinctive zones on Vulcano Island based on the distribution of houses and services and includes i) inhabited centres defined as clusters of houses with public infrastructures and services, ii) inhabited nuclei with a lower density of houses and with infrastructures poorly maintained and iii) scattered houses separated by a distance large enough not to be considered as a nucleus (Fig. 1). The census reports a total number of 1093 buildings over all these zones, amongst which 895 are residential houses and 64 used as public and tourism facilities. Although the census reports that most buildings were constructed during the 1970's to 1980 's, discussions with inhabitants and workers on the island revealed that most buildings were renewed over the years, making the true period of construction difficult to assess.

\section{Hazard assessment}

We present here a scenario-based hazard assessment for various eruptive styles built upon a detailed review of the stratigraphy. We used a modified version of TEPHRA2 (Bonadonna et al, 2005) allowing the input of flexible Total GrainSize Distributions (TGSD)(Biass et al, 2014). Each scenario presented here is 

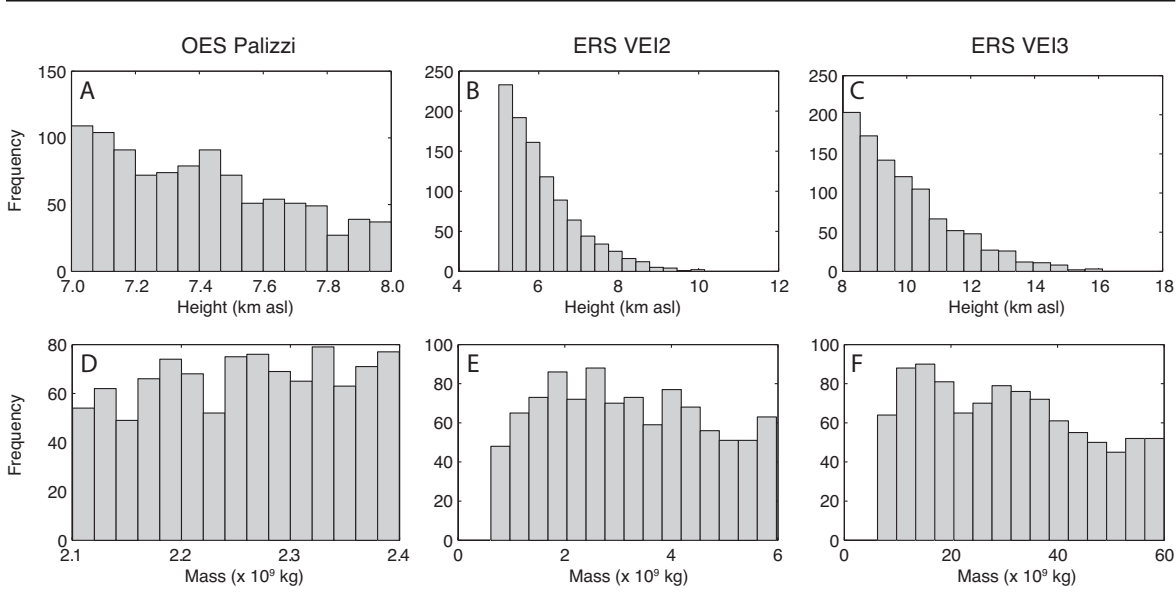

Fig. 3 Eruption source parameters for the sub-Plinian-type eruptions as produced by the sampling method of Biass et al (2014). A-C plume heights sampled on a logarithmic distribution; $\mathbf{D}-\mathbf{F}$ resulting erupted masses.

the result of 1,000 runs. We aim at quantifying the probability of exceeding a threshold of tephra accumulation given the occurrence of an eruption scenario. Section 3.1 presents the wind conditions for Vulcano Island, section 3.2 reviews the modelling strategy with TEPHRA2 and section 3.3 describes the probabilistic eruption scenarios identified for the activity at La Fossa Volcano.

\subsection{Wind conditions}

Wind conditions were inferred from the ECMWF ERA-Interim database (Dee et al, 2011) for the period 1980-2010 providing four daily profiles. Figure 2 shows the probability of wind to blow in a given direction (i.e. provenance + $180^{\circ}$ ) at a given velocity at sea level, 5,10 and $15 \mathrm{~km}$ asl. Two main observations can be made from the analysis of wind patterns. Firstly, a careful examination of the wind database shows no sign of seasonality below an altitude of 15-20 km asl, thus suggesting no need to perform additional season-based scenarios. Secondly, the wind direction gradually shifts from general SE trend at sea level to a E trend at an altitude of 2-3 $\mathrm{km}$ asl, which remains constant up to an altitude of $15-20 \mathrm{~km}$ asl. The same analysis performed with the NOAA NCEP/NCAR Reanalysis database (Kalnay et al, 1996) gave similar results.

\subsection{Modeling with TEPHRA2}

The TEPHRA2 model relies on an analytical solution of the advection-diffusion equation, which accounts for two different regimes of sedimentation based on the terminal fall velocity of particles (Bonadonna et al, 2005). TEPHRA2 requires the definition of the fall-time threshold (FTT) acting as a threshold for 
the sedimentation of small particles (power-law diffusion) and large particles (linear diffusion), in which case a diffusion coefficient must be specified. These empirical parameters were estimated by inverting field data with the method of Connor and Connor (2006). As any other analytical advection-diffusion model, TEPHRA2 does not describe the plume physics and is mostly based on the release of particles above the eruptive vent. As a result, TEPHRA2 has been applied to assess the hazard of both strong plumes (e.g. Tarawera volcano, New Zealand (Bonadonna et al. 2005); Cotopaxi volcano, Ecuador (Biass and Bonadonna 2013); Etna volcano, Italy (Scollo et al. 2015)) and weak plumes (e.g. Etna volcano, Italy (Scollo et al. 2015)) after a rigorous validation with field data for both types of plume (e.g., Bonadonna et al. 2005; Connor and Connor 2006; Scollo et al. 2008). A similar analytical model (i.e., HAZMAP) has been used to assess the hazard associated with both Vulcanian and co-PDC plumes at Soufrire Hills volcano, Montserrat (Bonadonna et al. 2002).

As any other analytical advection-diffusion model, TEPHRA2 does not describe the plume physics and is mostly based on the release of particles above the eruptive vent. As a result, TEPHRA2 has been applied to assess the hazard of both strong plumes (e.g. Tarawera volcano, New Zealand (Bonadonna et al, 2005); Cotopaxi volcano, Ecuador (Biass and Bonadonna, 2013); Etna volcano, Italy (Scollo et al, 2013)) and weak plumes (e.g. Etna volcano, Italy (Scollo et al, 2013)) after a rigorous validation with field data for both types of plume (e.g. Bonadonna et al, 2005; Connor and Connor, 2006; Scollo et al, 2009). A similar analytical model (i.e., HAZMAP) has been used to assess the hazard associated with both Vulcanian and co-PDC plumes at Soufrire Hills volcano, Montserrat (Bonadonna et al, 2002a).

Aggregation processes are known to affect deposition patterns by mobilizing fine particles into larger aggregates (e.g. Brown et al, 2012; Rose and Durant, 2011). For the Vulcanian and co-PDC plumes associated with the 1997 eruptive phase of Soufriere Hills volcano (Montserrat, West Indies), Bonadonna et al (2002a) demonstrated the necessity of accounting for aggregation processes in order to reproduce the observed fallout over the Island of Montserrat, without which models underestimate the tephra load on land. Based on observations of Bonadonna et al (2002a), we adopt the empirical parametrization of aggregation proposed by Biass et al (2014), which consists in removing a given fraction of fine ash (i.e. $\geq 4 \phi$ ), which is equally redistributed into $\phi$ classes $-1-3$ prior running the model. The amount of fine ash removed is here referred to as the aggregation coefficient and is stochastically sampled between $30-70 \%$ on a uniform distribution at each run Bonadonna et al (2002a,b, 2011b). The resulting TGSD is then written to a file and passed to TEPHRA2 as a separate input.

\subsection{Eruption scenarios}

Based on the description of the recent eruptive activity at La Fossa in section 2.1, we identified two potential eruptive scenarios for sub-Plinian and Vulca- 


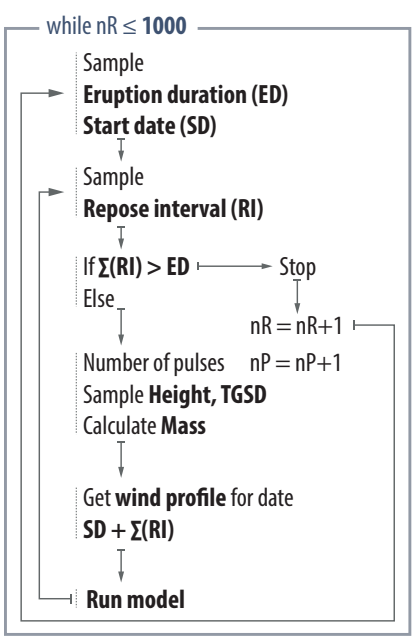

Fig. 4 Workflow used for the hazard assessment of longlasting Vulcanian cycles

nian styles, reflecting the activities of the Palizzi unit (PCEC) and the GCEC (Di Traglia et al, 2013), respectively. In each case, the best constrained eruptions of the considered cycle were used to quantify the scenarios. For clarity, all eruption scenarios are summarized in Table 1 and will be described in detail throughout sections 3.3.1 and 3.3.2.

\subsubsection{Sub-Plinian-type eruptions}

The review of the activity of the last 1,000 years presented in section 2.1 revealed the existence of two sub-Plinian units of similar physical characteristics and both suggesting a VEI 2 (Volcanic Explosivity Index; Newhall and Self, 1982). The probabilistic eruption scenarios applied here are those summarized in Bonadonna (2006) and include One Eruption Scenarios (OES) and Eruption Range Scenarios (ERS). We apply the method proposed by Biass et al (2014) to avoid unrealistic sets of Eruption Source Parameters (ESPs) arising from the independent sampling of plume heights and erupted masses. Firstly, an eruption date is sampled, from which the corresponding wind profile is obtained. Secondly, a plume height is sampled and combined with wind conditions to obtain the mass eruption rate (MER) with the method of Degruyter and Bonadonna (2012). Finally, an eruption duration is sampled and used to calculate a total erupted mass. If the mass falls within pre-defined boundaries, the set of ESPs is sent to the model, else a new set of ESPs is sampled. The rationale behind this approach is that, given that there is no theoretical relation between plume height and erupted mass, an independent and unconstrained sampling of these two ESPs could lead to unrealistic combinations. As a result, we chose to constrain the sampling based on the robust theoretical relationship between plume height and mass eruption rate (e.g. Sparks, 1986; Morton et al, 1956; Degruyter and Bonadonna, 2012). 
We start by assessing the fallout patterns following a typical sub-Plinian eruption as characterized from field studies (Di Traglia et al, 2013). Similarities in plume heights and masses between the two sub-Plinian eruptions suggest the application of a OES strategy allowing a narrow variation of ESPs (i.e. variations $<15 \%$ ). Plume heights were therefore sampled between 7 and 8 $\mathrm{km}$ asl and erupted mass between 2.1 and $2.4 \times 10^{9} \mathrm{~kg}$ (Table 2). The TGSD was reconstructed using the Voronoi method of Bonadonna and Houghton (2005) and Biass and Bonadonna (2014) based on the grain-size distributions at single outcrops produced by Di Traglia (2011), resulting in modes and sorting of about $-2 \phi$ and $1.5 \phi$. Since most points are proximal within a radius of $1.5 \mathrm{~km}$ around the vent, we consider $-2 \phi$ as the coarsest boundary of the median distribution, which we extend to $0 \phi$ (Table 2).

Second, we expand the ranges of the OES scenario to produce two ERS of VEI 2 and VEI 3 . The VEI 2 ERS spans wider ranges of plume height (5-12 $\mathrm{km} \mathrm{asl})$ and erupted mass $\left(0.6-6 \times 10^{9} \mathrm{~kg}\right.$; Table 2$)$ compared to the OES and thus allows for a larger aleatoric uncertainty (i.e. variations of ESPs $\geq 50 \%$ ). The VEI 3 ERS represents a scenario of higher magnitude (i.e. plume heights between 8-17 km asl and mass between 6-60 $\times 10^{9} \mathrm{~kg}$ ) which, even if not observed in the stratigraphy nor described in the chronicles of the last 1,000 years, is not excluded. In fact, a similar event occurred between 21 and $7 \mathrm{ka}$, with a column height of about $10 \mathrm{~km}$ and an erupted volume of $15 \times 10^{6} \mathrm{~m}^{3}$ (i.e. $9 \times 10^{9} \mathrm{~kg}$; Tufi di Grotte dei Rossi scoria fallout; Dellino et al, 2011). The TGSD for the VEI 2 ERS is based on the same considerations as for the OES, but a coarser boundary of $-3 \phi$ was set for the VEI 3 ERS to explore a larger aleatoric uncertainty on the TGSD (Table 2). The duration of all sub-Plinian scenarios was set between 30 minutes and 6 hours.

Figures $3 \mathrm{a}-\mathrm{c}$ show the distributions of plume heights for all sub-Plinian scenarios, resulting from a sampling constrained on a logarithmic distribution. Figures $3 \mathrm{~d}-\mathrm{f}$ summarize the erupted masses resulting from the application of the sampling method of Biass et al (2014). Note that the small difference in sampling frequencies between low and high erupted masses is a consequence of the sampling of eruption durations on a uniform distribution, which allows high erupted masses to be achieved both with combinations of high plumes/short duration or low plumes/long duration, the latter reflecting less vigorous climatic phases. Empirical parameters related to TEPHRA2 for the sub-Plinian eruptions were estimated by inverting the mass load provided by Di Traglia (2011). The inversion of both eruptions results in very similar results, suggesting diffusion coefficients and FTT of $1,500 \mathrm{~m}^{2} \mathrm{~s}^{-1}$ and $250 \mathrm{~s}$, respectively (Table 2).

\subsubsection{Vulcanian-type eruption}

In the context of Vulcanian eruptions, assessing the hazard related to tephra fallout is often achieved for single explosions (e.g. Sandri et al, 2014) and rarely for entire cycles (e.g. Bonadonna et al, 2002a). Although Vulcanian explosions typically release small amounts of ash in the atmosphere, their cyclic and 

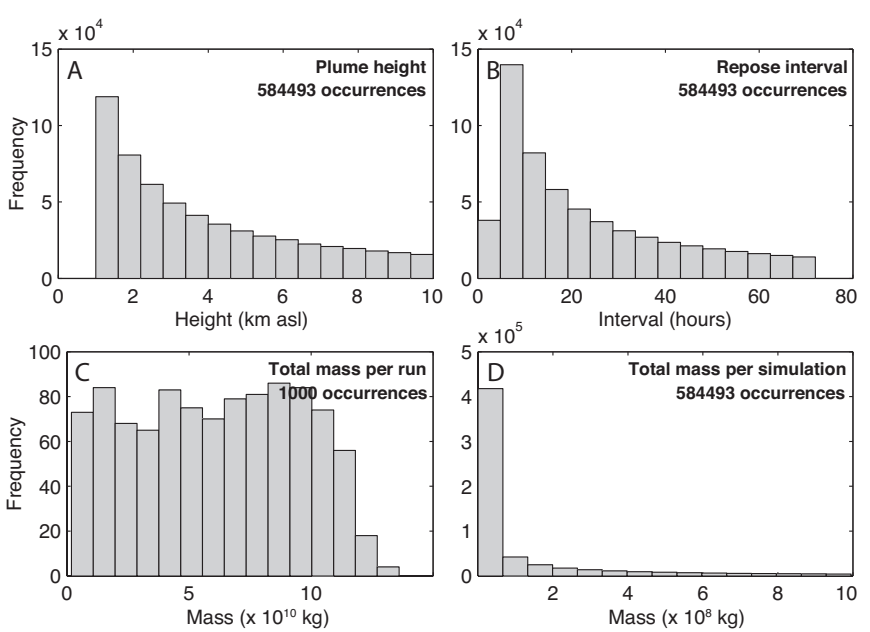

Fig. 5 Eruption source parameters for the Vulcanian V-LLERS eruption resulting from the algorithm shown in Fig. 4. A-B plume heights and repose intervals for each pulse, sampled on a logarithmic distribution; $\mathbf{C}-\mathbf{D}$ erupted mass per run and pulse, respectively.

\begin{tabular}{llllll}
\hline & Name & Acronym & ESP & Wind & Duration \\
\hline \multirow{2}{*}{ sub-Plinian } & One Eruption Scenario & OES & Fixed & Variable & Short \\
& Eruption Range Scenario & ERS & Variable & Variable & Short \\
& & & & & \\
\multirow{4}{*}{ Vulcanian } & Vulcanian Long-Lasting ERS & V-LLERS & Variable & Variable & Long \\
& Vulcanian OES & V-OES & Fixed & Variable & Short \\
\hline
\end{tabular}

Table 1 Summary of the probabilistic eruption scenarios used here. The ESP column describes the ranges used for the sampling of eruption source parameters. The Duration column describes the eruption duration either as short (i.e. $\leq 6 h$ ) or as long (i.e. $>6 h$ ). In the case of Vulcanian scenarios, explosion masses are calculated following equation 1.

repetitive nature can result in complex patterns of socio-economic vulnerability (e.g. Hillman et al, 2012; Rivera et al, 2010). We develop a method to quantify not only the hazard related to single explosions but to explore the variation of the potential hazards through time.

Figure 4 summarizes the workflow implemented to simulate a Vulcaniantype eruption, defined as a Vulcanian Long-Lasting Eruption Range Scenario (V-LLERS). Here, an explosion describes a single Vulcanian pulse, whereas an eruption describes an entire Vulcanian cycle with discrete explosions. In our probabilistic scenario, a run refers to an eruption. Eruption starting dates and durations are sampled at each run. Repose intervals between explosions are then sampled until their sums equal the eruption duration (Fig. 4). Repose intervals are converted into explosion dates, from which the corresponding wind profile is obtained. For each explosion, the median, standard deviation and aggregation coefficient used to create and modify the TGSD and a plume height are sampled. Due to the short duration of Vulcanian plumes, we follow the approach proposed by Bonadonna et al (2002a) that relates the height of 


\begin{tabular}{|c|c|c|c|c|c|c|c|}
\hline & \multicolumn{7}{|c|}{ Scenario } \\
\hline & \multicolumn{3}{|c|}{ sub-Plinian type } & \multicolumn{4}{|c|}{ Vulcanian type } \\
\hline & $\begin{array}{l}\text { OES } \\
\text { Pal B+D }\end{array}$ & $\begin{array}{l}\text { ERS } \\
\text { VEI 2 }\end{array}$ & $\begin{array}{l}\text { ERS } \\
\text { VEI 3 }\end{array}$ & V-LLERS & $\begin{array}{l}\text { V-OES } \\
1 \mathrm{~km}\end{array}$ & $\begin{array}{l}\text { V-OES } \\
5 \mathrm{~km}\end{array}$ & $\begin{array}{l}\text { V-OES } \\
10 \mathrm{~km}\end{array}$ \\
\hline Plume height (kma.s.l.) & $7-8^{l}$ & $5-12^{l}$ & $8-17^{l}$ & $1-10^{l}$ & 1 & 5 & 10 \\
\hline Mass $\left(\times 10^{9} \mathrm{~kg}\right)$ & $2.1-2.4$ & $0.6-6$ & $6-60$ & - & $2 \times 10^{-5}$ & $5 \times 10^{-2}$ & 0.9 \\
\hline$\phi$ range & $-4-8$ & $-4-8$ & $-4-8$ & $-4-8$ & $-4-8$ & $-4-8$ & $-4-8$ \\
\hline Median $\phi$ & $-2-0$ & $-2-0$ & $-3-0$ & $-1-1$ & $-1-1$ & $-1-1$ & $-1-1$ \\
\hline$\sigma \phi$ & $1-3$ & $1-3$ & $1-3$ & $1-3$ & $1-3$ & $1-3$ & $1-3$ \\
\hline Agg. coef. (\%) & $30-70$ & $30-70$ & $30-70$ & $30-70$ & $30-70$ & $30-70$ & $30-70$ \\
\hline$\rho$ lithic $\left(\mathrm{kg} \mathrm{m}^{-3}\right)$ & 2700 & 2700 & 2700 & 2700 & 2700 & 2700 & 2700 \\
\hline$\rho$ pumice $\left(\mathrm{kg} \mathrm{m}^{-3}\right)$ & 500 & 500 & 500 & 1000 & 1000 & 1000 & 1000 \\
\hline$\rho$ deposit $\left(k g m^{-3}\right)$ & 600 & 600 & 600 & 1200 & 1200 & 1200 & 1200 \\
\hline Diff. coef. $\left(m s^{-2}\right)$ & 1500 & 1500 & 1500 & 4900 & 4900 & 4900 & 4900 \\
\hline $\mathbf{F T T}(s)$ & 255 & 255 & 255 & 5000 & 5000 & 5000 & 5000 \\
\hline Duration & $.5-6 \mathrm{~h}$ & $.5-6 \mathrm{~h}$ & $.5-6 \mathrm{~h}$ & $30-1095 \mathrm{~d}$ & - & - & - \\
\hline Repose interval (hours) & - & - & - & $4-72^{l}$ & - & - & - \\
\hline
\end{tabular}

Table 2 Eruption source parameters for all eruption scenarios considered. ${ }^{l}$ denotes a stochastic sampling constrained on a logarithmic distribution in order to give more weight to the lowest boundary of the distribution. When unspecified, the stochastic sampling is achieved on a uniform distribution. The duration is indicated in hours for the sub-Plinian eruptions $(h)$ and in days for the long-lasting Vulcanian eruptions $(d)$. $\phi$ range, Median $\phi$ and $\sigma \phi$ : Range, median and standard deviation of the TGSD, respectively; Agg. coef.: Aggregation coefficient; $\rho$ lithic, $\rho$ pumice and $\rho$ deposit: Densities of the lithic, pumice clasts and whole deposit, respectively; Diff. coef.: Diffusion coefficient; FTT: Fall-time threshold. OES, ERS, $V-L L E R S$ and $V-O E S$ are described in the text and in Table 1. PAL $B$ and $P A L D$ refer to the Palizzi eruptions described in Section 3.

a thermal rising in the atmosphere with the plume mass with the following relationship (Woods and Kienle, 1994; Druitt et al, 2002):

$$
H=1.89 Q^{0.25}
$$

where $Q=f \times M \times C \times \Delta T$ is the excess thermal mass of the thermal injection, $f$ is the solid mass fraction capable of loosing heat to the plume, $M$ $(\mathrm{kg})$ is the plume mass, $C\left(J \mathrm{~kg}^{-1} \mathrm{~K}^{-1}\right)$ is the solids specific heat and $\Delta T$ $(K)$ is the initial temperature contrast between the erupted mixture and the surrounding air. For Soufriere Hills volcano (Montserrat), $f$ is taken as 0.8, $C$ is $1100 \mathrm{~J} \mathrm{~kg}^{-1} \mathrm{~K}^{-1}, \Delta T$ is $800 \mathrm{~K}$ (Bonadonna et al, 2002a; Druitt et al, 2002), and the relationship between the Vulcanian plume height and the mass of the plume can be expressed as:

$$
H=55 M^{0.25}+H_{V}
$$

where $H$ is the plume height ( $m$ a.s.l.), $M$ is the plume mass $(k g)$ and $H_{V}$ the vent height ( $m$ a.s.l.). Each explosion is modelled with TEPHRA2, and the mass accumulation at each run $\left(M_{i}\right.$, in $k g m^{-2}$, where $i=1 \ldots n R$ and $n R$ is the total number of runs) corresponds to the sum of the mass accumulation of individual explosions in that $\operatorname{run}\left(\operatorname{Mexpl}(x, y)_{j}\right.$, in $\mathrm{kg} \mathrm{m}^{-2}$, where $j=1 \ldots n E_{i}$ and $n E_{i}$ is the number of explosions in the $i-t h$ run): 


$$
M(x, y)_{i}=\sum_{j=1}^{n E_{i}} \operatorname{Mexpl}(x, y)_{j}
$$

where $x, y$ are geographical coordinates, $n R$ is the number of runs and $n E$ the number of explosions of a given run. We then quantify the probability of exceeding a critical mass accumulation threshold $M_{T}$ at coordinates $x, y$ as:

$$
P_{x, y}=\frac{\sum_{i=1}^{n R} K_{i}}{n R}
$$

where

$$
K_{i}= \begin{cases}1 & \text { if } M(x, y)_{i} \geq M_{T} \mid \text { eruption } \\ 0 & \text { otherwise }\end{cases}
$$

This method assumes no syn-eruptive erosion throughout one single eruption and therefore quantifies a maximum cumulative hazard associated with long-lasting eruptions. Although this is consistent with stratigraphic observations of Di Traglia et al (2013) that reveal scarce to null reworking during the 1888-90 eruptive cycle, this ignores clean-up operations.

Table 1 summarizes the ranges of ESPs defined for the Vulcanian-type scenario, which includes eruptive cycles that occurred between the XV century and 1890 at Vulcano, coinciding with the GCEC identified by Di Traglia et al (2013). Based on historical chronicles of De Fiore (1922) and Mercalli and Silvestri (1891), the duration of total Vulcanian cycles was set between 3 weeks and 3 years. Based on the observations of Mercalli and Silvestri (1891) during the 1888-90 eruption, we sample plume heights between 1-10 km asl on a logarithmic distribution (Fig. 5; Bianchi, 2007). Similarly, and according to the same sources, repose intervals were also sampled on a logarithmic distribution between 4 hours and 3 days. Note that Mercalli and Silvestri (1891) observe a positive relationship between the repose interval and the plume height of the following explosion, which is not accounted for in our method. The median and standard deviation of the initial TGSD were set to $-1-1$ and 1-3 $\phi$, respectively, based on the studies of the grain-size distributions at single outcrops (Di Traglia, 2011) and analogue volcanoes (e.g. Bonadonna et al, 2002b; Rose et al, 2007).

The workflow of Figure 4 ran with boundaries of ESPs specified in Table 2 results in a total of 584,493 explosions for 1,000 runs. Figure $5 \mathrm{c}$ and 5d show the erupted mass per run and explosion, respectively. In particular, the total mass per run ranges between $1.9 \times 10^{9}$ to $1.4 \times 10^{11} \mathrm{~kg}$, which covers well the ranges of masses inferred from Di Traglia (2011) for the Vulcanian fallout phases.

In addition to the V-LLERS, we also performed eruption scenarios to assess the fallout patterns of single Vulcanian explosions, deterministically setting the plume heights to 1,5 and $10 \mathrm{~km}$ asl. Equation 1 is applied for each plume height, resulting in masses of $3.8 \times 10^{4}, 5.7 \times 10^{7}$ and $1.0 \times 10^{9} \mathrm{~kg}$, respectively. These scenarios, called Vulcanian One Eruption Scenarios (V-OES), assess the 
hazard related to an eruption of a known size in variable wind conditions. ESPs are summarized in Table 2.

Since the field characterization of single explosions was not possible for any of the Vulcanian eruptions, we used the 1974 eruption of Fuego (Guatemala; Rose et al, 2007) as an analogue case to run the inversion and estimate appropriate empirical parameters of TEPHRA2 (i.e. FTT and diffusion coefficient). Although the 1974 eruption of Fuego resulted in higher plumes (14 km asl) and larger mass $\left(5.2 \times 10^{10} \mathrm{~kg}\right.$; Rose et al, 2007) than typical GCEC eruptions, it was characterized by a pulsatory activity and was classified between Vulcanian and sub-Plinian styles. We therefore consider it as a good analogue to Vulcanian eruptions. Best fits resulting from the inversion of the mass load suggest a diffusion coefficient of 4,900 $\mathrm{m} \mathrm{s}^{-2}$ and a FTT of 5,000 $s$ (Table 2).
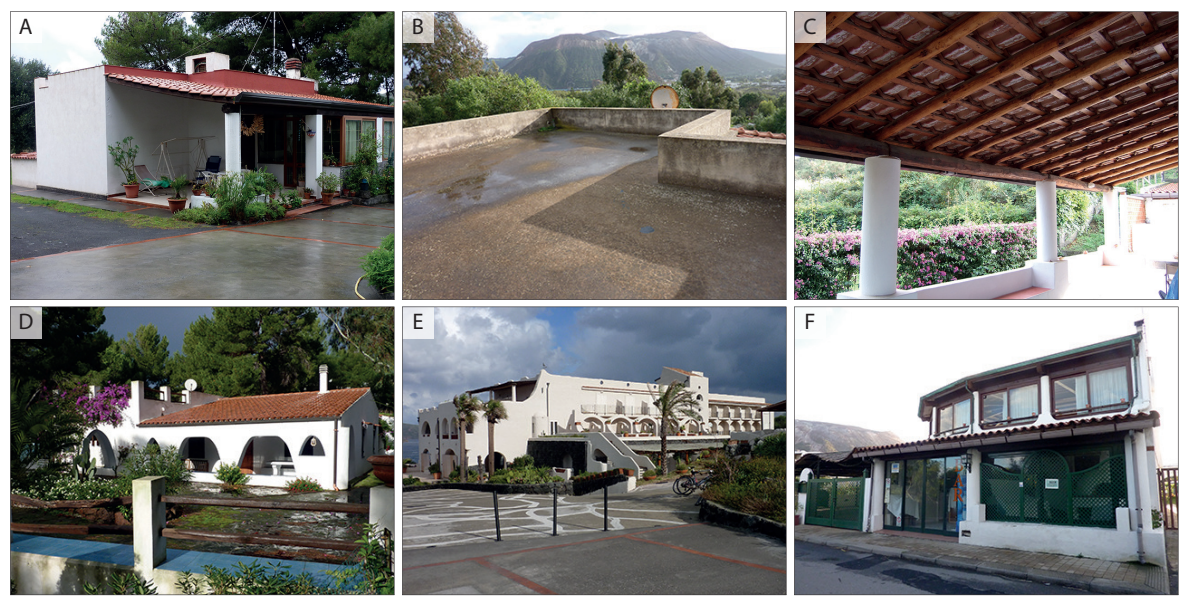

Fig. 6 Typical buildings on the island of Vulcano. A-C Most representative type of residential building, typically single-storey with a concrete flat roof $(\mathbf{B})$ and a timber front porch $(\mathbf{C})$. D residential building with a roof made of a timber structure and tiles. E Typical one to three storeys hotel complex and $\mathbf{F}$ typical commercial arcade in the Porto area. Following the classification of (Spence et al, 2005), buildings shown in A, B, C and $\mathrm{E}$ are classified as medium strong $(M S)$ or strong $(S T)$, and buildings $\mathrm{D}$ and $\mathrm{E}$ as weak $(W E)$ or medium weak $(M W)$.

\section{Vulnerability assessment of the built environment}

In addition to the 2000 census (ISTAT, 2005) described in section 2.2, we use two datasets for the building stock, including the building's footprints mapped from aerial images (courtesy of A. Galderisi and co-workers) and the field survey performed in the context of the ENSURE project (Bonadonna et al, 2011a). This survey detailed key characteristics of the most representative building within a $100 \times 100 \mathrm{~m}$ pixel, resulting in a total of 254 buildings. Key findings reveal that $70 \%$ have one floor, $73 \%$ consist of flat roofs and 


\begin{tabular}{|c|c|c|c|c|}
\hline \multirow[t]{2}{*}{ Roof class } & \multirow[t]{2}{*}{ Description } & \multirow[t]{2}{*}{$Q_{\text {mean }}(k P a)$} & \multicolumn{2}{|c|}{ Proportion per roofing stock } \\
\hline & & & Median & Strong \\
\hline WE (weak) & Tiled roof, old or in poor condition & 2.0 & $34.3 \%$ & $2.7 \%$ \\
\hline MW (medium weak) & Tiled roof, average or good condition & 3.0 & $44.1 \%$ & $18.9 \%$ \\
\hline MS (medium strong) & Flat RC roof & 4.5 & $18.9 \%$ & $44.1 \%$ \\
\hline ST (strong) & $\begin{array}{l}\text { Flat RC roof designed for access, } \\
\text { younger than } 20 \text { years }\end{array}$ & 7.0 & $2.7 \%$ & $34.3 \%$ \\
\hline
\end{tabular}

Table 3 Description of the roof classes of Spence et al (2005) adapted to the built environment of Vulcano described in Section 4. The vulnerability of each roof class is characterized by a mean load $Q_{\text {mean }}$ and a geometric standard deviation $Q_{s t d}$ of 0.2 . The composite model of Spence et al (2005) assumes that the roofing stock of any region in Europe can be described by a distribution of the four different roof classes, thus defining roofs stocks having probabilities of occurrence of $10 \%$ (weak), $50 \%$ ( $\mathrm{Me}$ dian) and $90 \%$ (Strong). Here, the proportions of the four roof classes are shown for the Median and Strong roofing stocks. $R C$ stands for reinforced concrete.

$54 \%$ have a regular morphology (i.e. square or rectangular footprint). These typical buildings are homogeneously spread over the different settled areas and are illustrated in Figure 6. Based on in situ observations and discussion with local builders, we assume that most flat roofs are composite slabs made of precast reinforced concrete joist and hollow clay blocks overlaid by an upper layer of concrete. The advantage of this type of slab is their rapid construction and relatively light weight. Additionally, these roofs are typically designed to allow an access and can therefore withstand loads of at least $150 \mathrm{~kg} \mathrm{~m}^{-2}$ (Jenkins et al, 2014).

The vulnerability of the building stock on Vulcano is assessed using the European tephra fallout roof vulnerability curves developed by Spence et al (2005). The study of Spence et al (2005), undertaken in the context of the EUfunded EXPLORIS project, relies on four European reference sites - Vesuvius (Italy), Sete Cidades (Azores), La Soufriere (Guadeloupe) and Teide (Canary Islands) - to assess the impact on the built environment to tephra fallout. Four general classes of roof types were defined and are presented in Table 3 and include weak $(W E)$, medium weak $(M W)$, medium strong $(M S)$ and strong $(S T)$. Note that in Table 3, the description of each roof class was adapted to best describe the buildings found on Vulcano. Each roof class is characterized by a mean collapse load $\left(Q_{\text {mean }}, k P a\right)$, and the vulnerability curves take the shape of:

$$
P(\text { collapse } \mid I)=\phi\left(\ln (I), \ln \left(Q_{\text {mean }}\right), \sigma\right)
$$

where $P_{\text {collapse }}$ is the probability of collapse of the exposed building, $I$ is a load of a given intensity $(k P a), \sigma$ is the geometric standard deviation fixed to 0.2 following Spence et al (2005) and $\phi$ is the cumulative density function of a Normal distribution (Spence et al, 2005; Jenkins et al, 2014). Figure 7 illustrates the fragility curves of Spence et al (2005) for each typical roof type. For the WE, $M W, M S$ and $S T$ roofs, a $50 \%$ probability of roof collapse is reached after accumulations of about $200,300,460$ and $710 \mathrm{~kg} / \mathrm{m}^{2}$, respectively. 


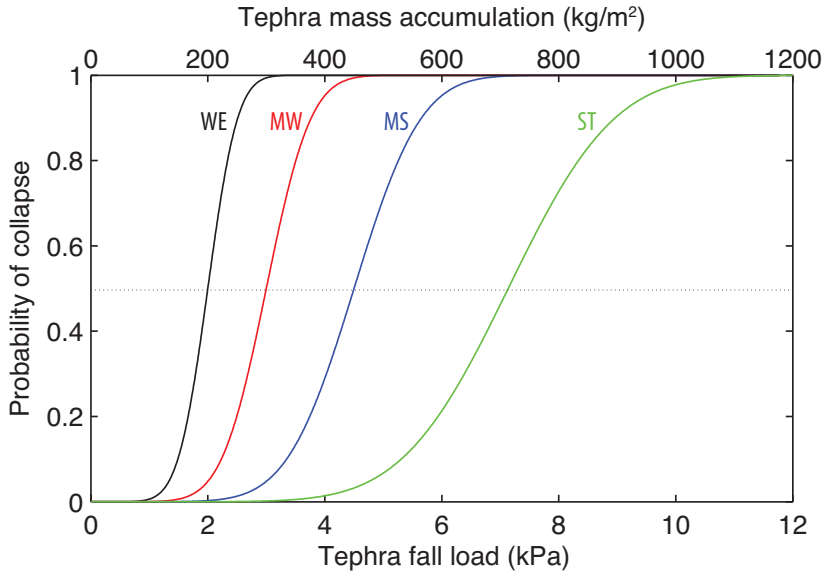

Fig. 7 Fragility curves for the roof types $W E$, $M W, M S$ and $S T$ of Spence et al (2005) as defined in Table 3, for which a $50 \%$ probability of collapse is reached following accumulations of about 200, 300, 460 and $710 \mathrm{~kg} / \mathrm{m}^{2}$, respectively.

The choice of the method of Spence et al (2005) over other existing approaches developed to assess the vulnerability of the built environment (e.g. Pomonis et al, 1999; Blong, 2003c; Jenkins et al, 2014) is based upon the fact that i) the region described by Spence et al (2005) corresponds best to our case-study and ii) Spence et al (2005) also developed composite vulnerability curves based on the assumption that the roofs in a given region may be distributed in any of the four classes summarized in Table 3. Based on extensive field investigations, Spence et al (2005) relate the quality of the roofing stock to their probabilities of occurrence in the European area, where the roofing stock is expressed as a proportion of any of the four roof classes described in Table 3. Typical Weak, Median and Strong roofing stocks were identified based on probabilities of occurrence $10 \%, 50 \%$ and $90 \%$ respectively, for which proportions of $W E, M W, M S$ and $S T$ roof classes are summarized in Table 3. The assessment realized for the ENSURE project compared to Table 3 suggests that the roofing stock on Vulcano has strengths between the typical Median and Strong roofing stocks, which are used to represent lower and upper boundaries of the confidence interval. The Weak roofing stock of Spence et al (2005) is therefore not considered here (although $W E$ roof classes are).

\section{Results}

\subsection{Hazard assessment}

Tables 1 and 2 summarize the eruption scenarios applied on the selected eruptions. We consider three hazardous thresholds of tephra accumulation. Firstly, we consider a value of $300 \mathrm{~kg} \mathrm{~m}^{-2}$ as a minimum threshold for roof collapse of the largest part of the built environment of Vulcano. Following Spence et al (2005), such an accumulation results in probabilities of collapse of $99 \%, 46 \%$, $4 \%$ and $0.2 \%$ for the roof types $W E, M W, M S$ and $S T$, respectively. However, 


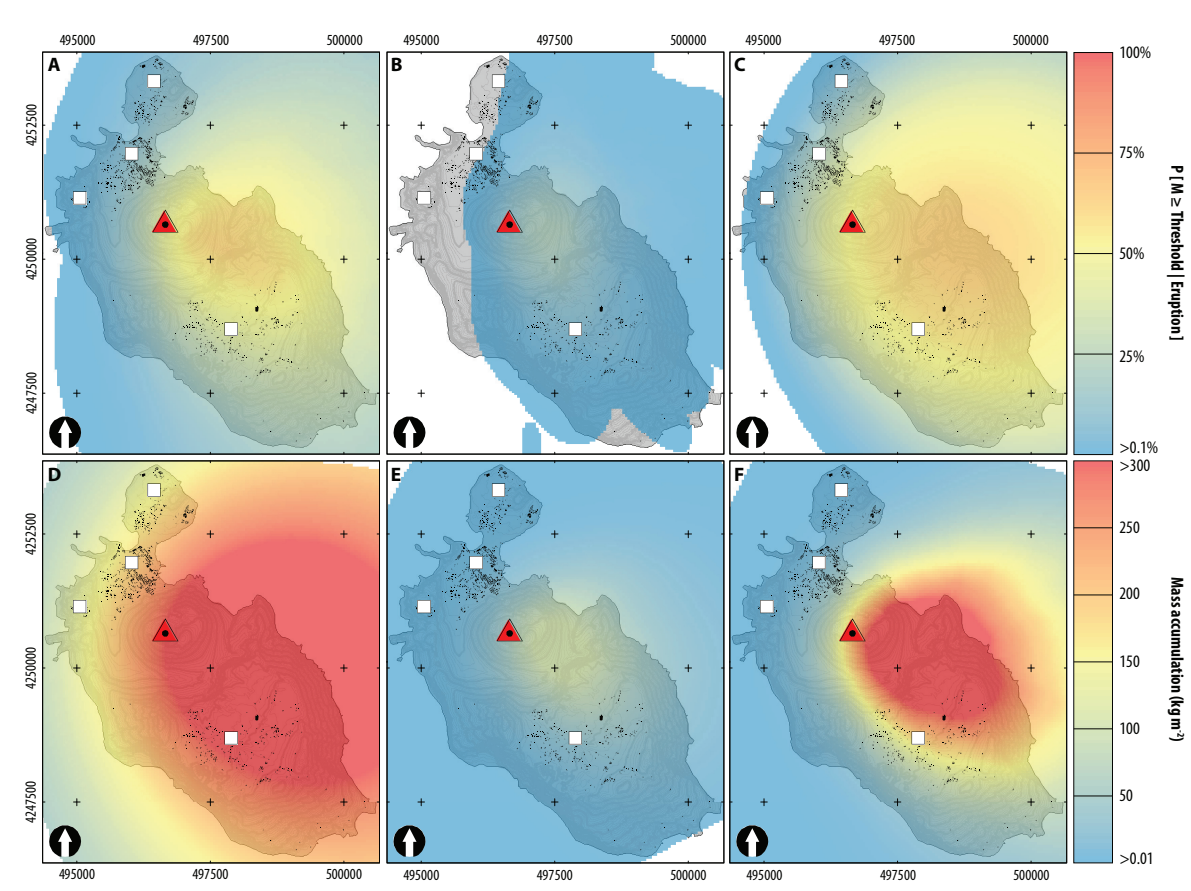

Fig. 8 A-C: Maps illustrating probabilities of exceeding an accumulation of $300 \mathrm{~kg} \mathrm{~m}^{-2}$ for the V-LLERS scenario (A), the ERS VEI 2 scenario (B) and the ERS VEI 3 scenario (C). D-F: Probabilistic isomass maps showing the tephra accumulation considering a 50\% probability of occurrence of the hazard for the V-LLERS scenario (D), the ERS VEI 2 scenario $(\mathbf{E})$ and the ERS VEI 3 scenario $(\mathbf{F})$. The built environment is also shown as black polygons and the main localities as white squares.

we recognized a few buildings with specifically large roof spans and poorly maintained roof structures. These specific cases include the school of Il Piano, which is likely to be used as a shelter during a crisis and for which we adopt a reduced threshold of $100 \mathrm{~kg} \mathrm{~m}^{-2}$. Finally, we also consider an accumulation of $10 \mathrm{~kg} \mathrm{~m} \mathrm{~m}^{-2}$ to illustrate other possible impacts than collapse on buildings, including damages of mechanical and electrical equipment (Jenkins et al, 2012; Wilson et al, 2011).

Hazard maps are compiled as i) probability maps to exceed a tephra accumulation and ii) probabilistic isomass maps showing a typical tephra accumulation for a given probability of occurrence of the hazard (Biass and Bonadonna, 2013). Figure 8 shows such hazard maps for selected scenarios and confirms the preferential SE dispersal suggested in Figure 2 for plume heights below $17 \mathrm{~km} \mathrm{asl}$, resulting in the northern part of Il Piano being the most likely area to be impacted by tephra fallout. The built environment is also shown for rapid exposure analysis. Figure $8 \mathbf{a}-\mathbf{c}$ shows the probability to exceed a tephra accumulation of $300 \mathrm{~kg} \mathrm{~m}^{-2}$ for the V-LLERS, the ERS VEI 2 and the ERS VEI 3 scenarios, respectively. Figure $8 \mathbf{d}-\mathbf{f}$ are probabilistic isomass maps showing a typical tephra accumulation for a probability 

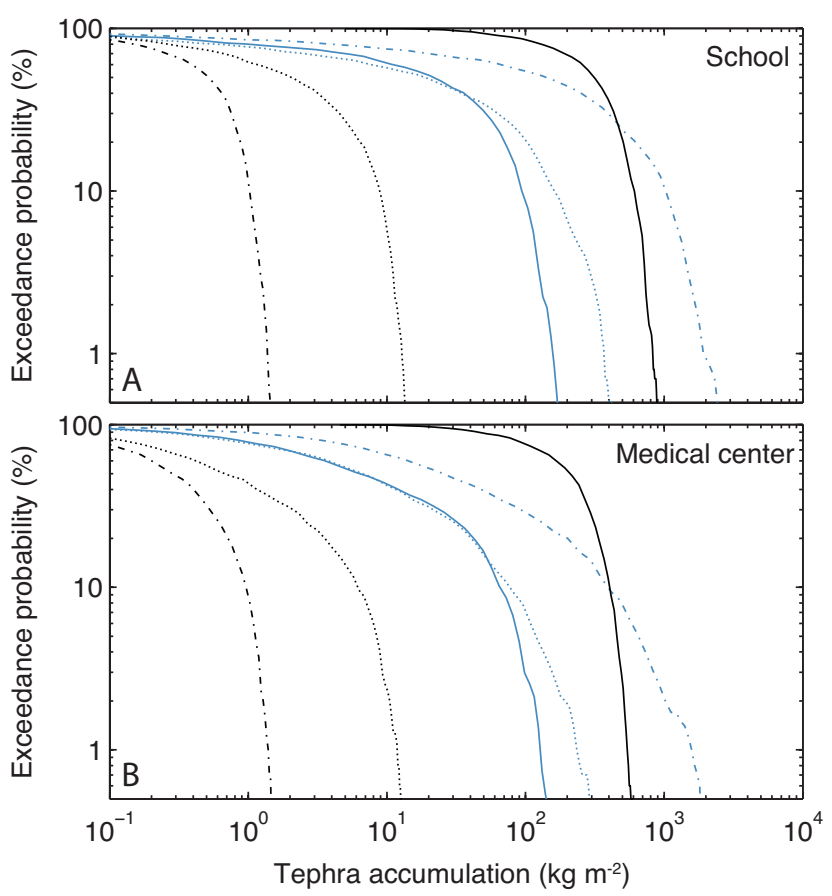

Fig. 9 Hazard curves for $\mathbf{A}$ the school of Il Piano (South) and $\mathbf{B}$ the medical center (North; see Fig. 1) for the scenarios defined in Table 2. Note that the V-OES $1 \mathrm{~km}$ plots be-

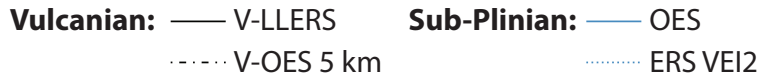
lations displayed here.

threshold of $50 \%$. Note that in the case of the V-LLERS scenario, these maps represent the hazard considering the total tephra deposition throughout the entire duration of a cycle without syn-eruptive reworking or the application of clean-up measures.

Figure $8 \mathbf{a}-\mathbf{c}$ suggests that Il Piano has $52 \%, 5 \%$ and $39 \%$ probability of exceeding a tephra accumulation of $300 \mathrm{~kg} \mathrm{~m}^{-2}$ and has a $50 \%$ probability of occurrence of tephra accumulations of 320,30 , and $160 \mathrm{~kg} \mathrm{~m}^{-2}$ for the V-LLERS, the ERS VEI 2 and the ERS VEI 3 scenarios, respectively. At the Porto area, which comprises the two principal evacuation harbours of Porto di Levante and Porto di Ponente (Fig. 1), these scenarios result in probabilities of $95 \%, 20 \%$ and $40 \%$ to exceed a tephra accumulation of $25 \mathrm{~kg} \mathrm{~m}^{-2}$, respectively, which can be problematic for the road network in case of emergency. Figure 9 presents hazard curves for the school of Il Piano (South) and the medical center (North; see Fig. 1) for all scenarios considered in Table 2. A V-LLERS has generally higher probabilities of tephra accumulation compared to a ERS VEI 3 up to accumulation values of about $500 \mathrm{~kg} \mathrm{~m}^{-2}$ at the school of Il Piano and $600 \mathrm{~kg} \mathrm{~m}^{-2}$ at the medical center, after which this trend is inverted. In the school area, these curves show that eruptions of V-OES $5 \mathrm{~km}$ and V-OES $10 \mathrm{~km}$ and a ERS VEI 2 eruption are not likely to cause a threat to roof structures. 


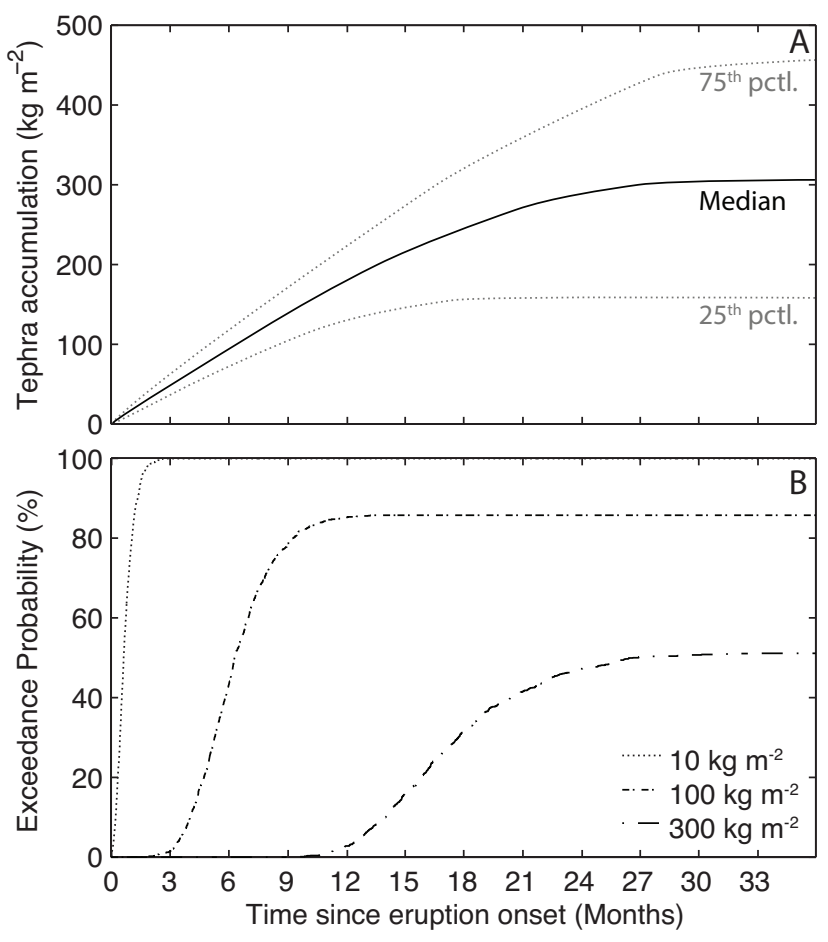

Fig. 10 Cumulative curves for long-lasting Vulcanian eruptions showing, for the school of Il Piano (Fig. 1), A the variation of tephra accumulation through time as the median, the $25^{\text {th }}$ and $75^{\text {th }}$ percentiles and $\mathbf{B}$ the variability of the probability of exceeding given tephra thresholds through time.

However, V-LLERS and ERS VEI 3 eruptions result in probabilities of $60 \%$ and $35 \%$ to exceed tephra accumulations of $300 \mathrm{~kg} \mathrm{~m}^{-2}$.

In the context of long-lasting Vulcanian cycles, planners and decisionmakers can potentially require estimates on the evolution of hazards through time in order to implement risk mitigation measures such as clean-up procedures. For this reason, we modified the workflow shown in Figure 4 to produce cumulative curves of tephra accumulation through time. For each run, the eruption date is brought to a time $t_{0}$ after which, based on the date of each pulse, it is possible to estimate the tephra accumulation at given times after the onset of the eruption. Figure 10a shows the variation in time of the median tephra accumulation at the school of Il Piano and the $25^{\text {th }}$ and $75^{\text {th }}$ percentiles as lower and upper intervals over the 1,000 runs. Such a curve helps to rapidly estimate the response time before the occurrence of a hazard of a given magnitude. In the case of Figure 10a, these curves suggest that impacts caused by an accumulation of $100 \mathrm{~kg} \mathrm{~m}^{-2}$ on the poorly maintained roof structures of the school could happen between 5-9 months after the onset of the eruption. Assuming no erosion, remobilisation, rainfall or clean-up, potential collapse related to an accumulation of $300 \mathrm{kgm}^{-2}$ would require at least 15 months. Figure 10b transmits a similar message but based on the probability of exceeding given thresholds of tephra accumulation. For example, curves in Figure 10b show that the potential impact associated with accumulations of 100 and $300 \mathrm{~kg} \mathrm{~m}^{-2}$ becomes significant after 3 and 10 months, respectively. 
Alternatively, these curves show the duration after which the maximum probability of suffering tephra accumulations of a given intensity is reached. In the case of the school, there is a maximum probability of $85 \%$ to exceed a tephra accumulation of $100 \mathrm{~kg} \mathrm{~m} \mathrm{~m}^{-2} 9$ months after the eruption onset.

\subsubsection{Impact of rainfall}

When considering the impact on the built environment, one of the principal hazards is the load produced on the roof resulting from the accumulation of tephra. This hazard can, in turn, be modified by the adsorption of water within the porosity of the tephra deposit resulting from rainfall. Macedonio and Costa (2012) formalized a simple approach to estimate the additional water load based on the saturation of the total porosity. Following the values proposed by Fiorillo and Wilson (2004) for the Vesuvius region, we use total porosities of 0.67 and 0.68 for Vulcanian and sub-Plinian deposits, respectively. Here, given the typical flat morphology of the roofs on the island of Vulcano and following Fiorillo and Wilson (2004), we use the water saturation assumption and consider an increase of the load related to the addition of water until the field capacity is reached (i.e. the maximum volume of water a given deposit can hold).

After the 1920's, the total volume of rainfall in Sicily decreased but the intensity of heavy torrential rainfall events of short duration increased (Arnone et al, 2013; Bonaccorso et al, 2005; Brunetti et al, 2001; Cannarozzo et al, 2006). We adopt the classification of Arnone et al (2013) to describe daily rainfall on Vulcano, which depends on the intensity $I\left(m m d^{-1}\right)$, and where $0.1 \leq I<4$ is a light event, $4 \leq I<20$ is a moderate event and $I \geq 20$ is a heavy-torrential event. Using these thresholds, we assess the additional load resulting from the addition of 4,20 and $50 \mathrm{~mm}$ of rain water. Arnone et al (2013) identify a dry season from April to September and a wet season during the remaining part of the year (Fig. 11). Hourly rainfall data for the period 2008-2013 collected at the Centro Operativo Marcello Carapezza on Vulcano (courtesy of INGV-Palermo) reflects this seasonal pattern and reveals that daily rainfalls of $0.1,4$, and $20 \mathrm{~mm}$ occurred respectively 633,241 and 14 times over the 2008-2013 period. Although daily rainfall of $50 \mathrm{~mm}$ is not observed, we consider the 6 year observation period as too limited to exclude such an extreme event.

Figure 12 shows the changes in load for the school of Il Piano and the medical center as a result of rainfall. Following a sub-Plinian eruption of VEI 2 , the medical center has a $7-8 \%$ probability of exceeding a mass load of $100 \mathrm{~kg} \mathrm{~m}^{-2}$ for a dry deposit. This probability increases to $10 \%$ and $15 \%$ if associated with rainfall episodes of 20 and $50 \mathrm{~mm}$, respectively. Figure 12 also reflects the inflection points identified by Macedonio and Costa (2012), which represents the field capacity (e.g. amount of water content held in the deposit) of the deposit for a given porosity. For instance, Figure $12 \mathbf{b}$ shows that for the ERS VEI2 and VEI3 sub-Plinian eruptions, $4 \mathrm{~mm}$ of rain will saturate the deposit up to an accumulation of about $10 \mathrm{~kg} \mathrm{~m}^{-2}$. 


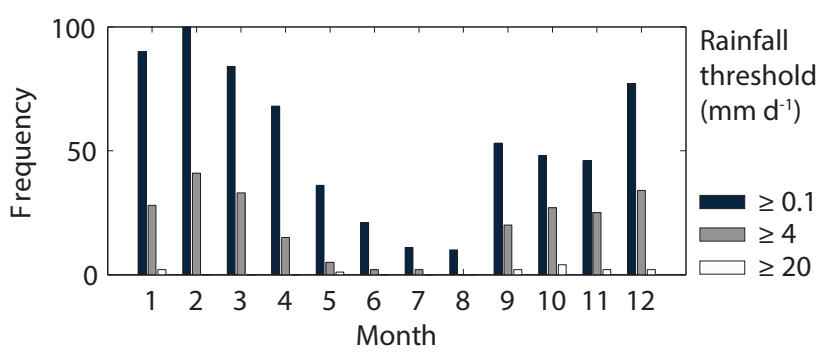

Fig. 11 Frequencies of daily rainfall exceeding $0.1,4$ and $20 \mathrm{~mm} \mathrm{~d}^{-1}$ based on hourly rainfall measurements for the period 2008-2013 at Vulcano (Data from INGV-Palermo).

\subsection{Impact on the built environment}

In order to assess the impact on the built environment, we first compiled probabilistic isomass maps for all eruption scenarios for probabilities of occurrence of $10 \%, 25 \%, 50 \%, 75 \%$ and $90 \%$ (see Fig $8 \mathrm{~d}-\mathrm{f}$ ). For each scenario and probability threshold, a tephra accumulation is retrieved for every mapped building (Fig. 1, Fig. 8). Using equation 4 on each building, these tephra accumulations are converted into four different probabilities of collapse assuming that any building can have either a weak (WE), medium weak (MW), medium strong (MS) or strong (ST) roof (Table 3). A composite probability of collapse is then calculated for each building by summing the product of the probabilities of collapse of each roof type multiplied by their proportions of occurrence for the Median and Strong roofing stocks of Spence et al (2005) (Table 3).

Figure 13 and Table 4 summarize the impact of the ERS VEI 3 and the V-LLERS eruptions. Results show that a ERS VEI 2 eruption does not affect the typical roofing stocks and is therefore not discussed here (Table 4). Figure 13 can be read as a box and whisker plot. Black dots indicate raw composite probabilities of collapse of separate buildings $(n=1093)$ calculated for a hazard occurring at a given probability of occurrence (x axis). The resulting distributions are displayed as the median (red line), the $25^{t h}-75^{t h}$ percentiles range (blue area) and the $10^{t h}-90^{t h}$ percentiles range (orange area). Table 4 shows the composite probability of collapse calculated for various percentiles over the distributions displayed in Figure 13. For instance, considering i) a VEI 3 eruption, ii) a $50 \%$ probability of occurrence of the hazard (PIM 50\%) and iii) a Median roofing stock, Table 4 shows that $90 \%$ of the roofs have a $\leq 10 \%$ probability of collapse, which also means that the remaining $10 \%$ have a $>10 \%$ probability of collapse. The potential increase of impact related to rainfall was also assessed by adding rainfall loads to the probabilistic isomass maps computed for the various probabilities of occurrence. The probability of collapse of a given building is then re-calculated using this new load.

Results show the limited impact of sub-Plinian ERS VEI2 and VEI3 eruptions considering either Median or Strong roofing stocks. Considering a tephra load occurring with a $10 \%$ probability, a VEI 3 eruption results in $90 \%$ of the roofs having probabilities of collapse $\leq 98 \%$ and $\leq 81 \%$ when considering $\mathrm{Me}$ dian and Strong roofing stocks, respectively (Table 4). However, these probabilities drop to $10 \%$ (Median) and 1\% (Strong) when a 50\% probability of 


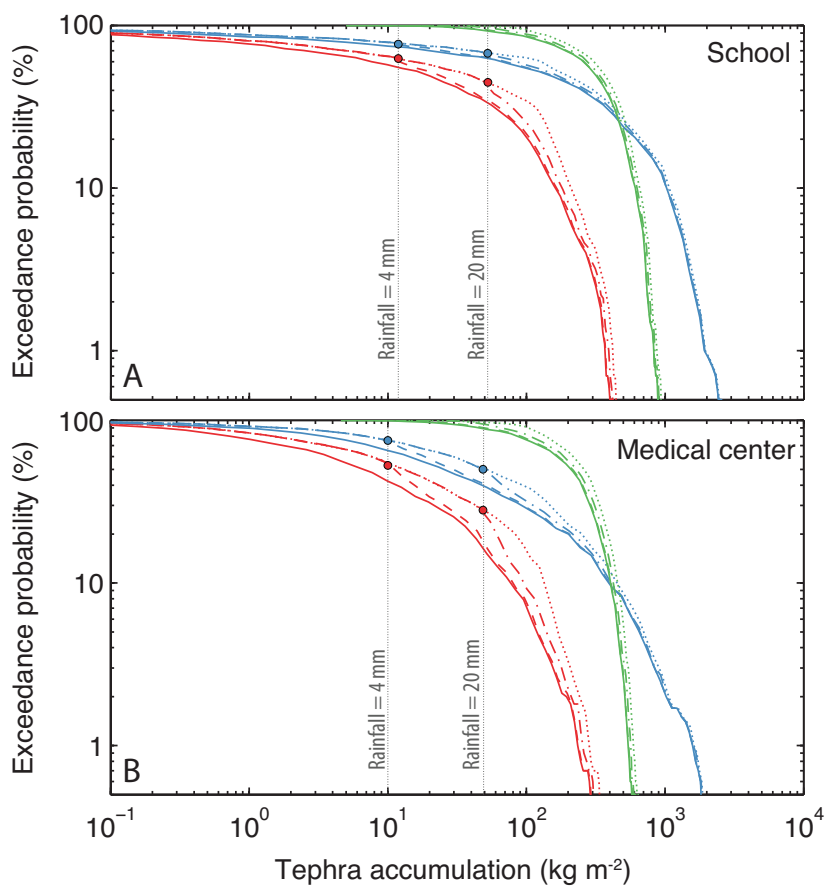

Dry $\quad 4 \mathrm{~mm} \quad 20 \mathrm{~mm} \quad 50 \mathrm{~mm}$

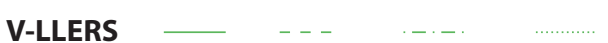

ERS VEI2

ERS VEI3
Fig. 12 Hazard curves for $\mathbf{A}$ the school of Il Piano (South) and $\mathbf{B}$ the medical center (North; see Fig. 1) for the VLLERS, ERS VEI 2 and the ERS VEI 3 scenarios (Table 2) considering the addition of 4,20 and $50 \mathrm{~mm}$ of rainfal (i.e. light, moderate and heavy-torrential events, respectively).

occurrence is considered for the same eruption. The impact resulting from entire Vulcanian cycles is significantly higher than for sub-Plinian events. Using a $50 \%$ probability occurrence and a Median roofing stock, Table 4 shows how $50 \%$ of the roofs could suffer $\leq 20 \%$ probability of collapse, and $90 \%$ of the stock has a $\leq 62 \%$. These values drop to $2 \%$ and $16 \%$ for a Strong roofing stock. Finally, Table 4 also shows the variation of the impact when 4, 20 and $50 \mathrm{~mm}$ of rainfall are added to the hazard occurring at a $50 \%$ probability (i.e. PIM 50\%). For all scenarios and roofing stocks, an addition of $4 \mathrm{~mm}$ does not significantly increase the impact compared to a dry deposit, but additions of 20 and $50 \mathrm{~mm}$ of rainfall result in significant increases in the probabilities of roof collapse (Table 4). 


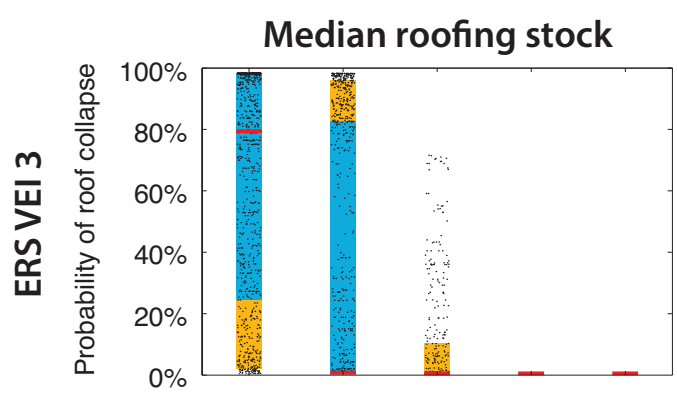

Strong roofing stock
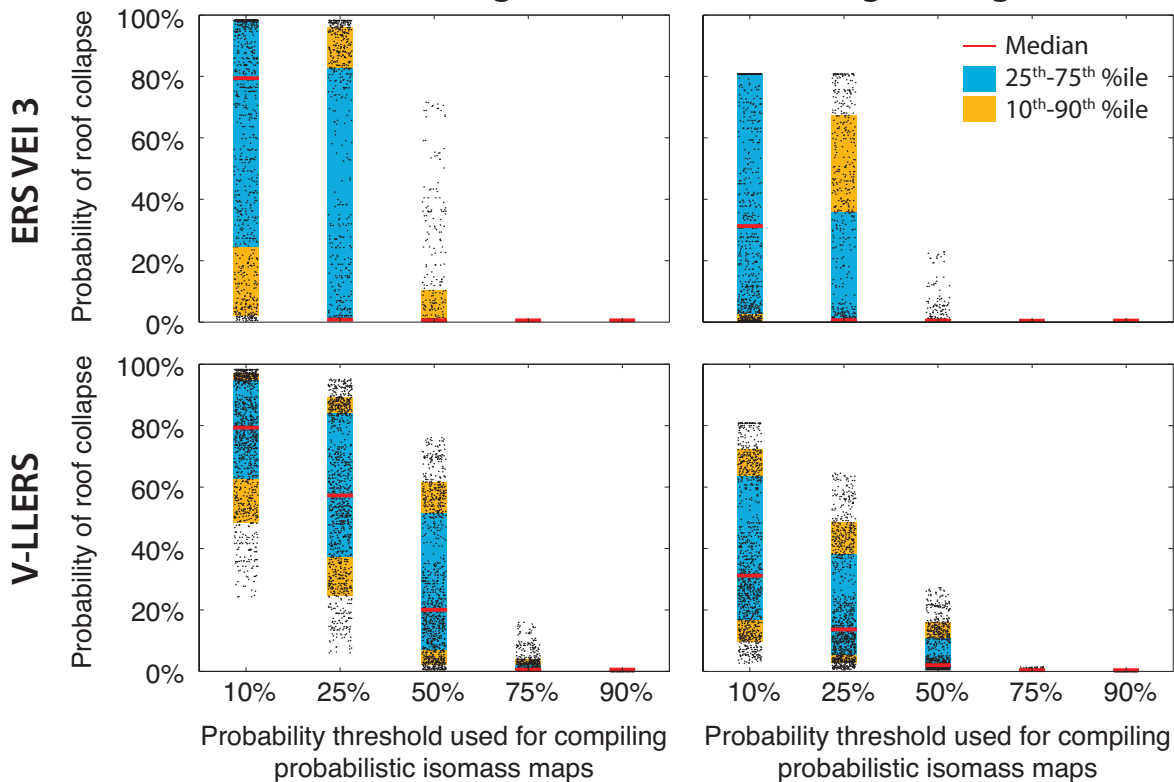

Probability threshold used for compiling probabilistic isomass maps

Fig. 13 Impact on the buildings following a ERS VEI3 eruption (top row), and a VLLERS eruption (bottom row) resulting from the application of the composite European vulnerability curves of Spence et al (2005) considering typical Median (left column) and strong (right column) roofing stocks (exceedence probabilities of $50 \%$ and $90 \%$, respectively). The $\mathrm{x}$-axis shows the probability threshold used to compile probabilistic isomass maps. Black dots show the probability of roof collapse of each building affected by the hazard occurring at a given probability (x axis). Distributions of probabilities for buildings overall are summarized as the median (red line), the $25^{t h}-75^{t h}$ interval (blue box) and the $10^{t h}-90^{t h}$ interval (orange box).

\section{Discussion}

Hazard from long-lasting Vulcanian eruptions

An innovative method to assess the hazard related to long-lasting eruptions is presented here. Time-based tephra accumulation and hazard curves (Fig. 10) allow to monitor the evolution of the hazard and the critical durations to reach hazardous levels of tephra load, with important implications on the compilation and implementation of effective policies of emergency management. The hazard is expressed as the evolution in time of both tephra accumulation and probabilities to exceed hazardous thresholds. For instance, Figures 10a and 10b show that a median accumulation of $100 \mathrm{~kg} \mathrm{~m}^{-2}$ has a $50 \%$ probability of occurrence to be reached 6 months after the eruption onset. Similarly, when considering the $75 \mathrm{th}$ and $25 \mathrm{th}$ of the tephra accumulation, $100 \mathrm{~kg} \mathrm{~m}^{-2}$ can be reached after 5 and 9 months, respectively, corresponding to probabilities of occurrence of $25 \%$ and $75 \%$ (Fig. 12b). 


\begin{tabular}{|c|c|c|c|c|c|c|c|c|c|c|c|}
\hline \multirow[b]{3}{*}{ Percentile } & & \multicolumn{10}{|c|}{ Probability of roof collapse (\%) } \\
\hline & & \multicolumn{5}{|c|}{ Median roofing stock } & \multicolumn{5}{|c|}{ Strong roofing stock } \\
\hline & & $10^{t h}$ & $25^{t h}$ & $50^{t h}$ & $75^{t h}$ & $90^{t h}$ & $10^{t h}$ & $25^{t h}$ & $50^{t h}$ & $75^{t h}$ & $90^{t h}$ \\
\hline \multirow[t]{8}{*}{ ERS VEI 2} & PIM $10 \%$ & 0 & 0 & 0 & 4 & 21 & 0 & 0 & 0 & 0 & 2 \\
\hline & PIM $25 \%$ & 0 & 0 & 0 & 0 & 0 & 0 & 0 & 0 & 0 & 0 \\
\hline & PIM $50 \%$ & 0 & 0 & 0 & 0 & 0 & 0 & 0 & 0 & 0 & 0 \\
\hline & PIM $75 \%$ & 0 & 0 & 0 & 0 & 0 & 0 & 0 & 0 & 0 & 0 \\
\hline & PIM $90 \%$ & 0 & 0 & 0 & 0 & 0 & 0 & 0 & 0 & 0 & 0 \\
\hline & $4 \mathrm{~mm}$ & 0 & 0 & 0 & 0 & 0 & 0 & 0 & 0 & 0 & 0 \\
\hline & $20 \mathrm{~mm}$ & 0 & 0 & 0 & 0 & 0 & 0 & 0 & 0 & 0 & 0 \\
\hline & $50 \mathrm{~mm}$ & 0 & 0 & 0 & 0 & 0 & 0 & 0 & 0 & 0 & 0 \\
\hline \multirow[t]{8}{*}{ ERS VEI 3} & PIM $10 \%$ & 2 & 24 & 79 & 98 & 98 & 0 & 3 & 31 & 81 & 81 \\
\hline & PIM $25 \%$ & 0 & 0 & 1 & 83 & 96 & 0 & 0 & 0 & 36 & 67 \\
\hline & PIM $50 \%$ & 0 & 0 & 0 & 0 & 10 & 0 & 0 & 0 & 0 & 1 \\
\hline & PIM $75 \%$ & 0 & 0 & 0 & 0 & 0 & 0 & 0 & 0 & 0 & 0 \\
\hline & PIM $90 \%$ & 0 & 0 & 0 & 0 & 0 & 0 & 0 & 0 & 0 & 0 \\
\hline & $4 \mathrm{~mm}$ & 0 & 0 & 0 & 0 & 13 & 0 & 0 & 0 & 0 & 1 \\
\hline & $20 \mathrm{~mm}$ & 0 & 0 & 0 & 1 & 19 & 0 & 0 & 0 & 0 & 2 \\
\hline & $50 \mathrm{~mm}$ & 0 & 0 & 0 & 5 & 32 & 0 & 0 & 0 & 1 & 5 \\
\hline \multirow[t]{8}{*}{ V-LLERS } & PIM $10 \%$ & 48 & 63 & 79 & 95 & 97 & 10 & 17 & 31 & 63 & 72 \\
\hline & PIM $25 \%$ & 24 & 37 & 57 & 84 & 89 & 3 & 6 & 14 & 38 & 48 \\
\hline & PIM $50 \%$ & 2 & 7 & 20 & 52 & 62 & 0 & 1 & 2 & 11 & 16 \\
\hline & PIM $75 \%$ & 0 & 0 & 0 & 2 & 4 & 0 & 0 & 0 & 0 & 0 \\
\hline & PIM $90 \%$ & 0 & 0 & 0 & 0 & 0 & 0 & 0 & 0 & 0 & 0 \\
\hline & $4 \mathrm{~mm}$ & 4 & 9 & 23 & 54 & 64 & 0 & 1 & 3 & 13 & 18 \\
\hline & $20 \mathrm{~mm}$ & 8 & 15 & 30 & 59 & 69 & 1 & 2 & 4 & 16 & 21 \\
\hline & $50 \mathrm{~mm}$ & 18 & 27 & 41 & 68 & 76 & 2 & 4 & 7 & 21 & 27 \\
\hline
\end{tabular}

Table 4 Summary of the impact considering typical Median and Strong roofing stocks for Vulcano. Values represent the probability calculated at given percentiles on the distributions shown in Fig. 13. PIM stands for Probabilistic Isomass Map. 4, 20 and $50 \mathrm{~mm}$ show the variability of the impact when same values of rainfall are added to the probabilistic isomass map compile for a $50 \%$ probability of occurrence.

Mercalli and Silvestri (1891) report accumulation rates during the last 1888-1890 eruption of 0.17 and $1.94 \mathrm{~kg} \mathrm{~m}^{2} \mathrm{~h}-1$ in the towns of Lipari (Lipari Island) and Porto (Vulcano Island), respectively, leading Di Traglia (2011) to argue that critical accumulation of tephra for roof collapse could be reached as rapidly as 15 days. Figure 10 suggests a longer duration to reach similar accumulations in Porto, where the medical center has a $50 \%$ probability of reaching an accumulation of $100 \mathrm{~kg} \mathrm{~m}^{-2}$ after minimum time of about one year should the total deposit remain intact. This discrepancy is probably due to i) Mercalli and Silvestri (1891) reporting maximum accumulation rates as well as ii) Di Traglia (2011) considering a threshold of $100 \mathrm{~kg} \mathrm{~m}^{-2}$ as critical for roof collapse, which appears to underestimate the strength of the roofing stocks in Vulcano according to the analyses of Spence et al (2005). Our results suggest that efficient clean-up operations could be sufficient to mitigate impact on buildings during and following a Vulcanian-type eruption. 
Hazard patterns associated with sub-Plinian and Vulcanian eruptions

This study reveals key differences in the time and spatial distribution of the hazard related to tephra fallout associated with sub-Plinian and Vulcanian eruptions, which reflects the different dynamics of these eruptive styles. Firstly, sub-Plinian eruptions consist of a sustained release of material over a short (i.e. minutes to hours) period of time associated with efficient fragmentation processes, resulting in plumes rising under the combined effect of both momentum and buoyancy. In contrast, single Vulcanian explosions are often considered as thermals, i.e. instantaneous release of material typically driven by impulsive fragmentation events producing mostly buoyancy-driven plumes, which result in a faster thinning rate of tephra deposits (Bonadonna et al, 2002b; Rose et al, 2007). Figure 9 reflects these differences, where the curves associated with a single Vulcanian explosion with a plume height of $10 \mathrm{~km}$ (i.e. V-OES 10; mass of $0.9 \times 10^{9} \mathrm{~kg}$ ) results in significantly smaller accumulation than a sub-Plinian eruption with a plume height of $7-8 \mathrm{~km}$ (i.e. OES; mass of $2.1-2.4 \times 10^{9} \mathrm{~kg}$ ). Secondly, sub-Plinian eruptions produce massive deposits controlled by wind conditions at the time of the eruption over short periods of time. In contrast, the total deposits produced by long-lasting Vulcanian eruptions are the result of the contribution of multiple discrete explosions typically producing thinner blankets of tephra and often result in circular isopachs (e.g. Bonadonna et al, 2002b). However, entire Vulcanian eruptions, here lasting between 3 weeks and 3 months, typically result in higher exceedance probabilities compared to subPlinian eruptions (e.g. ERS VEI3) up to a critical point after which the trend reverts. This critical point represents the threshold of tephra accumulation after which the combined contribution of all separate explosions of a Vulcanian eruptions is typically lower than the deposit produced by a short-lasting intense sub-Plinian eruption.

Emergency plans and mitigation measures designed for long-lasting Vulcanian eruptions thus need to account for daily disruptions of human activities for undefined periods of time and frequent clean-up operations (e.g. Montserrat, West Indies; Sakurajima, Japan; Sword-Daniels et al, 2014; Hayes et al, 2015). Similar patterns of disruptions can also be associated with long-lasting violent Strombolian eruptions (e.g. 1943-1952 eruption of Paricutin, Mexico, Blong, 1984; ongoing eruption of Etna, Italy, Scollo et al, 2009). As a result, communities are exposed to tephra fallout causing low direct impacts, but as a consequence of their repetitive nature, operational procedures need to be adapted to vulnerability patterns associated with long-lasting eruptions. Clean-up actions are a good illustration of the difference between operational procedures during short- and long-lasting eruptions. Magill et al (2013) report that in the context of the 2011 eruption of Shinmoedake (Japan), clean-up operations lasted for 8 months after the main eruptive phase of the 26-27 January in order to collect and handle the tephra that affected the approximately $106 \mathrm{~km}^{2}$ of urban area. Around volcanoes characterized by Vulcanian eruptions, although each explosion might result in the deposition of more limited amounts of material, repetitive clean-up operations must be implemented in 
order to preserve the functionality of critical infrastructures. At Sakurajima volcano (Japan), where daily explosions have occurred since the 1950's, roads are cleaned several times per day and the neighbouring city of Kagoshima is now equipped with resilient heating, ventilation and air conditioning systems able to remain functional with ashfalls $<5 \mathrm{~mm}$ (Wilson et al, 2011).

Impacts on agriculture also vary between short- and long-lasting eruptions. For short-lasting eruptions, Blong (1984) links various degrees of damages on the vegetation with critical thresholds of tephra accumulations up to consequences as severe as complete burial. Additionally, Jenkins et al (2014) confirm the importance of the timing of an eruption on the impact on crops, revealing the greatest impact if ashfall occurs during the harvesting season. Although violent Strombolian and Vulcanian eruptions rarely result in accumulations leading to a physical impact on plants, their repetitive nature results in fallouts potentially occurring throughout the entire year and the difficulties to implement efficient strategies to protect the cattle over a long-lasting crisis makes agricultural activities highly vulnerable to such eruptions. As an example, the 2006-2008 crisis at Ubinas volcano (Peru), losses due to cessation of agricultural activities was estimated to exceed 1,000,000 USD (Rivera et al, 2010).

Finally, regarding the hazard to aviation, four volcanoes frequently displaying violent Strombolian/Vulcanian styles and including Etna (Italy), Sakurajima (Japan), Popocatepetl (Mexico), and Soufriere Hills (Montserrat) have been identified as the most frequent sources of disruptions to airports (Guffanti et al, 2010, 2009). Adapted mitigation measures were developed and successfully implemented and include monitoring and aviation-warning systems of Onodera and Kamo (1994) for Sakurajima and Scollo et al (2009) for Etna.

\section{Impact assessment}

Typical roofing stocks for the European area (Spence et al, 2005) were used to estimate the potential vulnerability of the roofs to tephra fallout. Field investigations compared to the descriptions of the typical roofing stocks of Spence et al (2005) suggest that the built environment on Vulcano is situated somewhere between the Median and Strong roofing stocks. As a result, each building is characterized by a composite probability of collapse considering that it can consist of any of the four identified roof classes (i.e. WE, MW, MS and ST; Table 3), with probabilities of occurrence of each type defined by the European curves of Spence et al (2005). Therefore, the final probability of roof collapse of a given building should be regarded as a composite value accounting for the uncertainty related to the nature of the roof. Additionally, it is important to note that only damages to the roof structure are considered, and our method can not account for damages on additional structures such as roof overhangs.

The impact assessment is produced based on hazard levels obtained from probabilistic isomass maps extracted for a given probability of occurrence (Bi- 
ass et al, 2013; Biass and Bonadonna, 2013). The choice of the probability threshold, which can be regarded as an acceptable level of hazard, implies a critical choice related to decision-making policies and should not be decided by scientists. In order to illustrate the sensitivity of this method to the final impact, we express here the hazard (and the related impact) using various probability thresholds. Firstly, a median probability of $50 \%$ is used to express the central hazard value, implying that the hazard resulting from our probabilistic approach has $50 \%$ chance of being either smaller or larger than Figure $8 \mathrm{D}-\mathrm{F}$. Secondly, isomass maps with probability thresholds of $25 \%$ and $75 \%$ show the interquartile range, meaning that the hazard has $50 \%$ of probability to occur within this interval. Finally, probability thresholds of $10 \%$ and $90 \%$ were used to illustrate the $80 \%$ confidence interval.

The potential impact of tephra fallout on the built environment was compiled as box and whisker plots (Fig. 13) rather than a physical risk map for two reasons. Firstly, too many political implications lie behind a physical risk map, such as the choice of the probability thresholds for the hazard assessment and the potential risk zones. Secondly, box and whisker plots allow a global view of the stakes of the entire building stock and the variability associated with various probability thresholds.

\section{Caveats}

Our hazard and impact assessments are based on rigorous field studies and account for a range of potential eruption and atmospheric conditions. Nonetheless, we list some caveats below.

1. The scenario-based hazard assessment produced for La Fossa is conditional to the occurrence of an eruption, which differs from long-term hazard assessment in the sense that it does not account for a probability of occurrence of a given scenario (e.g. Marzocchi and Bebbington, 2012; Sandri et al, 2014). Eruption scenarios were identified based upon a detailed stratigraphic study of the deposits of the last 1,000 years associated with the activity at La Fossa volcano (Di Traglia et al, 2013; De Astis et al, 2013). Although 1,000 years is a limited geological time-window to assess the eruptive history of a given volcano, we included a VEI 3 sub-Plinian eruption, not observed within our studied interval but suggested to have occurred between 21 and $7 \mathrm{ka}$ (Dellino et al, 2011), to account for potential larger eruptions.

2. Although the present hazard assessment focuses on tephra fallout, the selected eruptions are likely to generate additional hazards. Typically, the opening phase of Vulcanian eruptions are associated with the generation of ballistic projectiles, witnessed to reach distances up to $2 \mathrm{~km}$ during the last 1888-1890 eruption (Mercalli and Silvestri, 1891; Bianchi, 2007; Dellino et al, 2011; Di Traglia et al, 2013), which would be critical for the Porto and Vulcanello areas. Additionally, the Porto area is under the threat of primary and secondary lahars for decades after the eruption, favoured by 
the impermeable nature of the substrate constituted by the Varicolori tuffs (Ferrucci et al, 2005). PDC deposits were also identified in the stratigraphy of the Commenda and GCEC cycles. The hazard assessment produced by Dellino et al (2011) and Doronzo and Dellino (2014) suggest that PDCs resulting from a hydrothermal eruption would be lethal in a zone covering the plain around La Fossa and below the Piano caldera. Furthermore, volcanic gases constitute a hazard even in the current unrest activity, which is likely to increase during the next crisis (Pareschi et al, 1999). Finally, we assume here a future activity located at La Fossa, but a potential reactivation of ancient systems such as Vulcanello is not excluded, which would be characterized by different patterns of hazard.

3. The method developed for the hazard assessment of long-lasting Vulcanian cycles results in a maximum hazard averaged over the entire duration of the cycle considering that no erosion nor clean-up measures occurred.

4. The method presented here for assessing the impact on the built environment should be viewed as a first-order assessment of the potential losses, which does not replace more detailed in situ studies, particularly for critical infrastructures. For instance, buildings with long spans, such as churches and schools, are likely to be used as emergency shelters during a crisis and, unless they are specifically designed to resist heavy loads, could potentially result in additional casualties. This aspect is specially relevant in the case of the school of Il Piano (Fig. 1), which is characterized by a poorlymaintained roofing structure and is located in the preferential dispersal of tephra. Similarly, this physical impact assessment should be put in a context of systemic vulnerability. For instance, the solar power-plant of Il Piano (Fig. 1) is likely to suffer damages with lower tephra accumulations than those suggested by Spence et al (2005), which could result in critical power shortages during an emergency.

\section{Conclusion}

This study presents a scenario-based hazard assessment for La Fossa volcano based on a detailed stratigraphic analysis of deposits formed during the last 1,000 years and a subsequent physical impact assessment on the built environment. The main outcomes include:

- The identification of the most likely scenarios potentially causing hazards related to tephra fallout, including sub-Plinian and Vulcanian eruptive styles;

- The quantification of hazard in both dry conditions and associated with various typical intensities of rainfall in Sicily;

- A new strategy for quantifying the hazard associated with long-lasting Vulcanian eruptions, including cumulative hazard curves that allows forecasting the evolution of the hazard through time, potentially assisting the implementation of mitigation measures such as clean-up procedures; 
- A first-order probabilistic impact assessment relying on typical roofing stocks developed by Spence et al (2005), which allows to quantify the potential degree of impact related to roof collapse.

Our probabilistic hazard assessment shows that:

- The preferential wind toward SE makes the Il Piano area is the most likely to suffer heavy tephra accumulations;

- The school of Il Piano has about $60 \%$ and $35 \%$ probabilities of being subjected to tephra accumulations exceeding $300 \mathrm{~kg} \mathrm{~m}^{-2}$ following Vulcanian (i.e. entire cycle) or sub-Plinian eruptions of VEI 3, respectively, a level taken to represent the onset of damage for the built environment on Vulcano according to Spence et al (2005). However, the general poor level of maintenance of many roofs on Vulcano could be damaged from accumulations of $100 \mathrm{~kg} \mathrm{~m} \mathrm{~m}^{-2}$, which have probabilities of occurrence of $>80 \%$ and $60 \%$ for the same scenarios;

- If roofs are not periodically cleaned during eruption sequence, an accumulation of $100 \mathrm{~kg} \mathrm{~m}^{-2}$ could be reached at the school within 5-9 months during a long-lasting Vulcanian eruption. At the same location, such an eruption there would results in negligible probabilities of exceeding accumulations of $300 \mathrm{~kg} \mathrm{~m}^{-2}$;

- Following a sub-Plinian VEI 3 eruption, half of the building stock has a $10 \%$ chance that there will be a $30 \%-80 \%$ probability of collapse; ;

- Similar probabilities result from the tephra accumulation related to entire Vulcanian cycles;

- The impact is mostly unchanged by the addition of $4 \mathrm{~mm}$ of rainfall but significantly increases with $20 \mathrm{~mm}$. Fortunately, such higher rainfall amounts are most likely to occur during the wet season, when tourist numbers are low.

Acknowledgements We are grateful to C. Frischknecht, H. Monnard, A. Cuomo and I. Manzella for providing the results of the building survey, to A. Galderisi for the building shapefiles, to L. Chevalley et C. Haenggeli for their help in the characterization of the built environment, to W.I. Rose for providing data on the 1974 Fuego eruption, to the INGVPalermo for the rainfall data, to Lorenzo Diana for the expertise on roof types, to L. Pioli for the insightful comments and to S. Jenkins and L. Sandri for their constructive reviews. All computations were performed on the Baobab cluster of the University of Geneva. S. Biass is supported by a SNF grant (\#200021-129997).

\section{References}

Arnone E, Pumo D, Viola F, Noto LV, La Loggia G (2013) Rainfall statistics changes in Sicily. Hydrol Earth Syst Sci 17(7):2449-2458, DOI 10.5194/hess17-2449-2013, URL http://www.hydrol-earth-syst-sci.net/17/2449/2013/ http://www.hydrol-earth-syst-sci.net/17/2449/2013/hess-17-2449-2013.pdf

Arrighi S, Tanguy JC, Rosi M (2006) Eruptions of the last 2200 years at Vulcano and Vulcanello (Aeolian Islands, Italy) dated by high-accuracy archeomagnetism. Physics of the Earth and Planetary Interiors 159(34):225-233 
Barberi F, Neri A, Valenza M, Villari L (1991) 1987-1990 unrest at Vulcano. Acta Vulcanologica (1):95-106

Bianchi L (2007) Leruzione 1888-1890 di Vulcano (Isole Eolie):Analisi stratigrafica, fisica e composizionale dei prodotti. Unpublished msc thesis, Università di Pisa

Biass S, Bonadonna C (2013) A fast GIS-based risk assessment for tephra fallout: the example of Cotopaxi volcano, Ecuador-Part I: probabilistic hazard assessment. Natural Hazards 65(1):477-495

Biass S, Bonadonna C (2014) TOTGS: Total grainsize distribution of tephra fallout. URL https://vhub.org/resources/3297

Biass S, Frischknecht C, Bonadonna C (2013) A fast GIS-based risk assessment for tephra fallout: the example of Cotopaxi volcano, Ecuador - Part II: vulnerability and risk assessment. Natural Hazards 65(1):497-521

Biass S, Scaini C, Bonadonna C, Folch A, Smith K, Höskuldsson A (2014) A multi-scale risk assessment for tephra fallout and airborne concentration from multiple Icelandic volcanoes - Part 1: Hazard assessment. Nat Hazards Earth Syst Sci 14(8):2265-2287, DOI 10.5194/nhess-14-22652014, URL http://www.nat-hazards-earth-syst-sci.net/14/2265/2014/ http://www.nat-hazards-earth-syst-sci.net/14/2265/2014/nhess-14-22652014.pdf

Blong R (2003a) A New Damage Index. Nat Hazards 30:1-23

Blong R (2003b) A Review of Damage Intensity Scales. Nat Hazards 29:57-76

Blong R (2003c) Building damage in Rabaul, Papua New Guinea, 1994. Bulletin of Volcanology 65(1):43-54

Blong RJ (1984) Volcanic hazards. A sourcebook on the effects of eruptions. Academic Press, Orlando

Bonaccorso B, Cancelliere A, Rossi G (2005) Detecting trends of extreme rainfall series in Sicily. Advances in Geosciences (2):7-11

Bonadonna C (2006) Probabilistic modelling of tephra dispersion. Statistics in volcanology pp 243-259

Bonadonna C, Houghton B (2005) Total grain-size distribution and volume of tephra-fall deposits. Bull Volcanol 67(5):441-456

Bonadonna C, Macedonio G, Sparks R (2002a) Numerical modelling of tephra fallout associated with dome collapses and Vulcanian explosions: application to hazard assessment on Montserrat. In: Druitt T, Kokelaar B (eds) The eruption of Soufrière Hills Volcano, Montserrat, from 1995 to 1999, vol 21, memoirs of edn, Geological Society of London, London, pp 483-516

Bonadonna C, Mayberry G, Calder E, Sparks R, Choux C, Jackson P, Lejeune A, Loughlin S, Norton G, Rose WI, Ryan G, Young S (2002b) Tephra fallout in the eruption of Soufrière Hills Volcano, Montserrat. In: Druitt T, Kokelaar B (eds) The eruption of Soufrière Hills Volcano, Montserrat, from 1995 to 1999, vol 21, memoirs of edn, Geological Society of London, pp 483-516

Bonadonna C, Connor CB, Houghton BF, Connor L, Byrne M, Laing A, Hincks TK (2005) Probabilistic modeling of tephra dispersal: Hazard assessment of a multiphase rhyolitic eruption at Tarawera, New Zealand. J Geophys Res 110(10.1029) 
Bonadonna C, Biass S, Manzella I, Galderisi A, Ceudech A, Ferrara F, Delmonaco G, Menoni S, Minucci G, Belvaux M, Manceau J, Montfort-Climent D, Sabourault P, Foerster E (2011a) Application of an integrated vulnerability conceputal approachm Del. 5.3.3: Development of the Integrated Approach on the Vulcano case study. Tech. Rep. 212045, Ensure project. Tech. rep.

Bonadonna C, Genco R, Gouhier M, Pistolesi M, Cioni R, Alfano F, Hoskuldsson A, Ripepe M (2011b) Tephra sedimentation during the 2010 Eyjafjallajökull eruption (Iceland) from deposit, radar, and satellite observations. J Geophys Res 116(B12):B12,202

Brown R, Bonadonna C, Durant A (2012) A review of volcanic ash aggregation. Physics and Chemistry of the Earth, Parts A/B/C 45-46(0):65-78

Brunetti M, Colacino M, Maugeri M, Nanni T (2001) Trends in the daily intensity of precipitation in Italy from 1951 to 1996. International Journal of Climatology 21(3):299-316

Cannarozzo M, Noto L, Viola F (2006) Spatial distribution of rainfall trends in Sicily (19212000). Physics and Chemistry of the Earth, Parts A/B/C 31(18):1201-1211, DOI 10.1016/j.pce.2006.03.022, URL http://www.sciencedirect.com/science/article/pii/S1474706506003019

Chester DK, Degg M, Duncan AM, Guest JE (2000) The increasing exposure of cities to the effects of volcanic eruptions: a global survey. Global Environmental Change Part B: Environmental Hazards 2(3):89-103

Chester DK, Dibben CJ, Duncan AM (2002) Volcanic hazard assessment in western Europe. Journal of Volcanology and Geothermal Research 115(3-4):411-435, DOI 10.1016/S0377-0273(02)00210-X, URL http://www.sciencedirect.com/science/article/pii/S037702730200210X

Chiodini G, Cioni R, Marini L, Panichi C (1995) Origin of the fumarolic fluids of Vulcano Island, Italy and implications for volcanic surveillance. Bulletin of Volcanology 57(2):99-110

Connor LJ, Connor CB (2006) Inversion is the key to dispersion: understanding eruption dynamics by inverting tephra fallout. Statistics in volcanology $p$ 231

Davi M, Rosa R, Donato P, Vetere F, Barca D, Cavallo A (2009) Magmatic Evolution and plumbing system of ring-fault volcanism: the Vulcanello Peninsula (Aeolian Islands, Italy). European Journal of Mineralogy 21(5):1009-1028

De Astis G, Lucchi F, Dellino P, La Volpe L, Tranne CA, Frezzotti ML, Peccerillo A (2013) Chapter 11 Geology, volcanic history and petrology of Vulcano (central Aeolian archipelago). Geological Society, London, Memoirs 37(1):281-349, DOI 10.1144/M37.11, URL http://mem.lyellcollection.org/content/37/1/281.abstract

De Fiore O (1922) Vulcano (Isole Eolie). In: Friedlaender I (ed) Revisita Vulcanologica (Suppl. 3), pp 1-393

De La Cruz-Reyna S, Meli RP, Quaas RW (2000) Volcanic crises management. In: Sigurdsson H, Houghton BF, Ballard RD (eds) Encyclopedia of Volcanoes, Academic press, San Diego, pp 1199-1214 
Dee DP, Uppala SM, Simmons AJ, Berrisford P, Poli P, Kobayashi S, Andrae U, Balmaseda MA, Balsamo G, Bauer P, Bechtold P, Beljaars ACM, van de Berg L, Bidlot J, Bormann N, Delsol C, Dragani R, Fuentes M, Geer AJ, Haimberger L, Healy SB, Hersbach H, Hólm EV, Isaksen L, Kållberg P, Köhler M, Matricardi M, McNally AP, MongeSanz BM, Morcrette JJ, Park BK, Peubey C, de Rosnay P, Tavolato C, Thépaut JN, Vitart F (2011) The ERA-Interim reanalysis: configuration and performance of the data assimilation system. Quarterly Journal of the Royal Meteorological Society 137(656):553-597, DOI 10.1002/qj.828, URL http://dx.doi.org/10.1002/qj.828

Degruyter W, Bonadonna C (2012) Improving on mass flow rate estimates of volcanic eruptions. Geophys Res Lett 39(16), DOI 10.1029/2012GL052566

Dellino P, La Volpe L (1997) Stratigrafia, dinamiche eruttive e deposizionali, scenario eruttivo e valutazioni di pericolosità a La Fossa di Vulcano. Tech. rep., CNR-Gruppo Nazionale per la Vulcanologia, Volume speciale VulcanoProgetto triennale 19931995

Dellino P, Astis G, Volpe L, Mele D, Sulpizio R (2011) Quantitative hazard assessment of phreatomagmatic eruptions at Vulcano (Aeolian Islands, Southern Italy) as obtained by combining stratigraphy, event statistics and physical modelling. Journal of Volcanology and Geothermal Research 201(14):364-384

Di Traglia F (2011) The last 1000 years of eruptive activity at the Fossa Cone (Island of Vulcano, Southern Italy). PhD thesis

Di Traglia F, Pistolesi M, Rosi M, Bonadonna C, Fusillo R, Roverato M (2013) Growth and erosion: The volcanic geology and morphological evolution of La Fossa (Island of Vulcano, Southern Italy) in the last 1000 years. Geomorphology 194(0):94107, DOI http://dx.doi.org/10.1016/j.geomorph.2013.04.018, URL http://www.sciencedirect.com/science/article/pii/S0169555X13002249

Doronzo DM, Dellino P (2014) Pyroclastic density currents and local topography as seen with the conveyer model. Journal of Volcanology and Geothermal Research 278-279:25-39, DOI 10.1016/j.jvolgeores.2014.03.012, URL http://www.sciencedirect.com/science/article/pii/S0377027314000997

Douglas J (2007) Physical vulnerability modelling in natural hazard risk assessment. Natural Hazards and Earth System Sciences

Druitt TH, Young SR, Baptie B, Bonadonna C, Calder ES, Clarke AB, Cole PD, Harford CL, Herd RA, Luckett R, Ryan G, Voight B (2002) Episodes of cyclic Vulcanian explosive activity with fountain collapse at Soufrière Hills Volcano, Montserrat. In: Druitt $\mathrm{T}$, Kokelaar B (eds) The eruption of Soufrière Hills Volcano, Montserrat, from 1995 to 1999, vol 21, Geological Society of London, London, pp 281-306, DOI 10.1144/GSL.MEM.2002.021.01.13, URL http://mem.lyellcollection.org/content/21/1/281.abstract

Ferrucci M, Pertusati S, Sulpizio R, Zanchetta G, Pareschi M, Santacroce R (2005) Volcaniclastic debris flows at La Fossa Volcano (Vulcano Island, southern Italy): Insights for erosion behaviour of loose py- 
roclastic material on steep slopes. Journal of Volcanology and Geothermal Research 145(3-4):173-191, DOI 10.1016/j.jvolgeores.2005.01.013, URL http://www.sciencedirect.com/science/article/pii/S0377027305000272

Fiorillo F, Wilson R (2004) Rainfall induced debris flows in pyroclastic deposits, Campania (southern Italy). Engineering Geology 75(34):263-289

Frazzetta G, La Volpe L, Sheridan MF (1983) Evolution of the Fossa Cone, Vulcano. Journal of Volcanology and Geothermal Research 17(1-4):329-360, DOI 10.1016/0377-0273(83)90075-6, URL http://www.sciencedirect.com/science/article/pii/0377027383900756

Frazzetta G, Gillot PY, Volpe L, Sheridan MF (1984) Volcanic hazards at Fossa of Vulcano: Data from the last 6,000 years. Bulletin Volcanologique 47(1):105-124, DOI 10.1007/BF01960543, URL http://dx.doi.org/10.1007/BF01960543

Fusillo R, Di Traglia F, Gioncada A, Pistolesi M, Wallace P, Rosi M (2015) Deciphering post-caldera volcanism: insight into the Vulcanello (Island of Vulcano, Southern Italy) eruptive activity based on geological and petrological constraints. Bulletin of Volcanology 77(9):1-23, DOI 10.1007/s00445015-0963-6, URL http://dx.doi.org/10.1007/s00445-015-0963-6

Granieri D, Carapezza M, Chiodini G, Avino R, Caliro S, Ranaldi M, Ricci T, Tarchini L (2006) Correlated increase in CO2 fumarolic content and diffuse emission from La Fossa crater (Vulcano, Italy): Evidence of volcanic unrest or increasing gas release from a stationary deep magma body? Geophysical Research Letters 33(13):L13,316

Guffanti M, Mayberry GC, Casadevall TJ, Wunderman R (2009) Volcanic hazards to airports. Natural Hazards 51(2):287-302

Guffanti M, Casadevall TJ, Budding K (2010) Encounters of Aircraft with Volcanic Ash Clouds: A Compilation of Known Incidents, 19532009. Tech. rep., USGS Data Series 545, URL http://pubs.usgs.gov/ds/545/

Gurioli L, Zanella E, Gioncada A, Sbrana A (2012) The historic magmatichydrothermal eruption of the Breccia di Commenda, Vulcano, Italy. Bulletin of Volcanology pp 1-20

Hayes JL, Wilson TM, Magill C (2015) Tephra fall clean-up in urban environments. Journal of Volcanology and Geothermal Research 304:359-377, DOI 10.1016/j.jvolgeores.2015.09.014, URL http://www.sciencedirect.com/science/article/pii/S0377027315002930

Hillman SE, Horwell CJ, Densmore AL, Damby DE, Fubini B, Ishimine Y, Tomatis M (2012) Sakurajima volcano: a physico-chemical study of the health consequences of long-term exposure to volcanic ash. Bulletin of Volcanology 74(4):913-930, DOI 10.1007/s00445-012-0575-3, URL http://dx.doi.org/10.1007/s00445-012-0575-3

ISTAT (2005) Progetto Census 2000 - Aggiornamento delle basi territoriali, Descrizione dei dati. Tech. rep.

Jenkins S, Magill C, McAneney J, Blong R (2012) Regional ash fall hazard I: a probabilistic assessment methodology. Bulletin of Volcanology pp 1-14

Jenkins S, Spence R, Fonseca J, Solidum R, Wilson T (2014) Volcanic risk assessment: Quantifying physical vulnerability in the 
built environment. Journal of Volcanology and Geothermal Research 276:105-120, DOI 10.1016/j.jvolgeores.2014.03.002, URL http://www.sciencedirect.com/science/article/pii/S0377027314000729

Jenkins SF, Wilson TM, Magill C, Miller V, Stewart C, Blong R, Marzocchi W, Boulton M, Bonadonna C, Costa A (2015) Volcanic ash fall hazard and risk. In: Loughlin S, Sparks S, Brown S, Jenkins S, Vye-Brown C (eds) Global Volcanic Hazards and Risk, Cambridge University Press, pp 173-222, URL http://dx.doi.org/10.1017/CBO9781316276273.005

Kalnay EC, Kanamitsu M, Kistler R, Collins W, Deaven D, Gandin L, Iredell M, Saha S, White G, Woollen J (1996) The NCEP/NCAR 40-year reanalysis project. Bulletin of the American Meteorological Society 77(3):437-471

Keller J (1970) Geological map of the Vulcano Island (Aeolian Islands). Litografia artistica cartografica, Firenze

Keller J (1980) The island of Vulcano. Rendiconti Società Italiana Mineralogia e Petrologia 36:369-414

Macedonio G, Costa A (2012) Brief Communication "Rain effect on the load of tephra deposits". Natural Hazards and Earth System Science 12(4):1229 1233

Magill C, Wilson T, Okada T (2013) Observations of tephra fall impacts from the 2011 Shinmoedake eruption, Japan. Earth, Planets, and Space 65:677698, DOI 10.5047/eps.2013.05.010

Marzocchi W, Bebbington M (2012) Probabilistic eruption forecasting at short and long time scales. Bull Volcanol 74(8):1777-1805

Menoni S, Molinari D, Parker D, Ballio F, Tapsell S (2012) Assessing multifaceted vulnerability and resilience in order to design risk-mitigation strategies. Natural Hazards 64(3):2057-2082, DOI 10.1007/s11069-012-0134-4, URL http://dx.doi.org/10.1007/s11069-012-0134-4

Mercalli G, Silvestri O (1891) Le eruzioni dell'Isola di Vulcano incominciate il 3 agosto 1888 e terminate il 22 marzo 1890, relazione scientifica. Ann Ufficio Centrale Metereol Geodin Ital 10:1-213

Morton BR, Taylor G, Turner JS (1956) Turbulent Gravitational Convection from Maintained and Instantaneous Sources. Proceedings of the Royal Society of London Series A Mathematical and Physical Sciences 234(1196):1-23, DOI 10.1098/rspa.1956.0011, URL http://rspa.royalsocietypublishing.org/content/234/1196/1.abstract

Newhall CG (2000) Volcano warnings. In: Sigurdsson H, Houghton BF, Ballard RD (eds) Encyclopaedia of volcanoes, Academic Press, San Diego, pp 11851197

Newhall CG, Self S (1982) The volcanic explosivity index (VEI)- An estimate of explosive magnitude for historical volcanism. Journal of Geophysical Research 87(C2):1231-1238

Onodera S, Kamo K (1994) Aviation safety measures for ash clouds in Japan and the system of Japan Air Lines for monitoring eruptions at Sakurajima volcano. US Geol Surv Bull 2047:213-219

Pareschi M, Ranci M, Valenza M, Graziani G (1999) The assessment of volcanic gas hazard by means of numerical models: An example from Vulcano 
Island (Sicily). Geophysical Research Letters 26(10):1405-1408

Piochi M, De Astis G, Petrelli M, Ventura G, Sulpizio R, Zanetti A (2009) Constraining the recent plumbing system of Vulcano (Aeolian Arc, Italy) by textural, petrological, and fractal analysis: The 1739 A.D. Pietre Cotte lava flow. Geochemistry, Geophysics, Geosystems 10(1):Q01,009, DOI 10.1029/2008GC002176, URL http://dx.doi.org/10.1029/2008GC002176

Pomonis A, Spence R, Baxter P (1999) Risk assessment of residential buildings for an eruption of Furnas Volcano, Sao Miguel, the Azores. Journal of volcanology and geothermal research 92(1-2):107-131

Pyle D (1989) The thickness, volume and grainsize of tephra fall deposits. Bull Volcanol 51(1):1-15

Rivera M, Thouret JC, Mariño J, Berolatti R, Fuentes J (2010) Characteristics and management of the 20062008 volcanic crisis at the Ubinas volcano (Peru). Journal of Volcanology and Geothermal Research 198(12):19-34

Rose W, Durant A (2011) Fate of volcanic ash: Aggregation and fallout. Geology 39(9):895-896

Rose WI, Self S, Murrow PJ, Bonadonna C, Durant AJ, Ernst GGJ (2007) Nature and significance of small volume fall deposits at composite volcanoes: Insights from the October 14, 1974 Fuego eruption, Guatemala. Bulletin of Volcanology 70(9):1043-1067, DOI 10.1007/s00445-007-0187-5, URL http://dx.doi.org/10.1007/s00445-007-0187-5

Sandri L, Thouret JC, Constantinescu R, Biass S, Tonini R (2014) Long-term multi-hazard assessment for El Misti volcano (Peru). Bulletin of Volcanology 76(2):1-26, DOI 10.1007/s00445-013-0771-9, URL http://dx.doi.org/10.1007/s00445-013-0771-9

Scollo S, Coltelli M, Prestifilippo M, D'Agostino M, Spata G (2009) Monitoring and forecasting Etna volcanic plumes. DOI 10.5194/nhess-9-1573-2009

Scollo S, Coltelli M, Bonadonna C, Del Carlo P (2013) Tephra hazard assessment at Mt. Etna (Italy). Natural Hazards and Earth System Sciences 13(12):3221-3233, DOI 10.5194/nhess-13-3221-2013

Simkin T, Siebert L (1994) Volcanoes of the World. Geoscience Press, Tucson, AZ

Sparks R (1986) The dimensions and dynamics of volcanic eruption columns. Bull Volcanol 48(1):3-15

Spence R, Kelman I, Brown A, Toyos G, Purser D, Baxter P (2007) Residential building and occupant vulnerability to pyroclastic density currents in explosive eruptions. Natural Hazards and Earth System Sciences 7(2):219230

Spence R, Komorowski JC, Saito K, Brown A, Pomonis A, Toyos G, Baxter P (2008) Modelling the impact of a hypothetical sub-Plinian eruption at La Soufrière of Guadeloupe (Lesser Antilles). Journal of Volcanology and Geothermal Research 178(3):516-528, DOI 10.1016/j.jvolgeores.2008.03.016, URL http://www.sciencedirect.com/science/article/pii/S0377027308001169

Spence RJS, Pomonis A, Baxter PJ, AW C (1996) Building damage caused by the Mount Pinatubo eruption of June 15, 1991, University of Washington 
Press, Seattle, pp 1053-1061

Spence RJS, Kelman I, Baxter PJ, Zuccaro G, Petrazzuoli S (2005) Residential building and occupant vulnerability to tephra fall. Natural Hazards and Earth System Sciences 5(4):477-494

Sword-Daniels V, Wilson TM, Sargeant S, Rossetto T, Twigg J, Johnston DM, Loughlin SC, Cole PD (2014) Chapter 26 Consequences of long-term volcanic activity for essential services in Montserrat: challenges, adaptations and resilience. Geological Society, London, Memoirs 39(1):471-488, URL http://mem.lyellcollection.org/content/39/1/471.abstract

Wilson T, Stewart C, Sword-Daniels V (2011) Volcanic ash impacts on critical infrastructure. Phys Chem Earth Pt A/B/C

Woods AW, Kienle J (1994) The dynamics and thermodynamics of volcanic clouds: Theory and observations from the april 15 and april 21, 1990 eruptions of redoubt volcano, Alaska. Journal of Volcanology and Geothermal Research 62(1-4):273-299, DOI 10.1016/0377-0273(94)90037-X, URL http://www.sciencedirect.com/science/article/pii/037702739490037X

Zuccaro G, Cacace F, Spence RJS, Baxter PJ (2008) Impact of explosive eruption scenarios at Vesuvius. Journal of volcanology and geothermal research 178(3):416-453 